\title{
Quasiperiodic $\sim 5-60$ s fluctuations of VLF signals propagating in the Earth-ionosphere waveguide: A result of pulsating auroral particle precipitation?
}

\author{
D. L. Carpenter, ${ }^{1}$ M. Galand, ${ }^{2,3}$ T. F. Bell, ${ }^{1}$ V. S. Sonwalkar, ${ }^{1,4}$ U. S. Inan, ${ }^{1}$ \\ J. LaBelle, ${ }^{5}$ A. J. Smith, ${ }^{6}$ T. D. G. Clark, ${ }^{7}$ and T. J. Rosenberg ${ }^{8}$
}

\begin{abstract}
Subionospheric very low frequency and low-frequency (VLF/LF) transmitter signals received at middle-latitude ground stations at nighttime were found to exhibit pulsating behavior with periods that were typically in the $\sim 5-$ $60 \mathrm{~s}$ range but sometimes reached $\sim 100 \mathrm{~s}$. The amplitude versus time shape of the pulsations was often triangular or zigzag-like, hence the term "zigzag effect." Variations in the envelope shape were usually in the direction of faster development than recovery. Episodes of zigzag activity at Siple, Antarctica ( $L \sim 4.3)$, and Saskatoon, Canada $(L \sim 4.2)$, were found to occur widely during the predawn hours and were not observed during geomagnetically quiet periods. The fluctuations appeared to be caused by ionospheric perturbations at the $\sim 85 \mathrm{~km}$ nighttime VLF reflection height in regions poleward of the plasmapause. We infer that in the case of the Saskatoon and Siple data, the perturbations were centered within $\sim 500 \mathrm{~km}$ of the stations and within $\sim 100-200 \mathrm{~km}$ of the affected signal paths. Their horizontal extent is inferred to have been in the range $\sim 50-200 \mathrm{~km}$. The assembled evidence, supported by Corcuffs [1996] recent research at Kerguelen $(L \sim 3.7)$, suggests that the underlying cause of the effect was pulsating auroral precipitation. The means by which that precipitation produces ionospheric perturbations at $85 \mathrm{~km}$ is not yet clear. Candidate mechanisms include (1) acoustic waves that propagate downward from precipitation regions above the $\sim 85 \mathrm{~km} \mathrm{VLF}$ reflection level; (2) quasi-static perturbation electric fields that give rise to $\mathbf{E x B}$ drifts of the bottomside ionosphere; (3) secondary ionization production and subsequent decay at or below $85 \mathrm{~km}$. Those zigzag fluctuations exhibiting notably faster development than recovery probably originated in secondary ionization produced near $85 \mathrm{~km}$ by the more energetic $(E>40 \mathrm{keV})$ electrons in the incident electron spectrum.
\end{abstract}

\section{Introduction}

In recent years, subionospherically propagating $\sim 20-$ $50 \mathrm{kHz}$ signals from very low frequency and low-frequency (VLF/LF) communication transmitters have increasingly been used as probes of ionospheric processes that occur near $\sim 85 \mathrm{~km}$, the inferred nighttime upper re-

\footnotetext{
${ }^{1}$ Space, Telecommunications and Radioscience Laboratory, Stanford University, Stanford.

${ }^{2}$ Centre d'Etude des Phénomènes Aléatoires et Géophysiques, Saint-Martin d'Hères, France.

${ }^{3}$ Now at National Center for Atmospheric Research, Boulder, Colorado.

${ }^{4}$ Now at Electrical Engineering Department, University of Alaska Fairbanks, Fairbanks.

${ }^{5}$ Department of Physics and Astronomy, Dartmouth College, Hanover, New Hampshire.

${ }^{6}$ British Antarctic Survey, Natural Environment Research Council, Cambridge, England.

${ }^{7}$ British Geological Survey, Natural Environment Research Council, Edinburgh, United Kingdom.

${ }^{8}$ Institute for Physical Science and Technology, University of Maryland, College Park.

Copyright 1997 by the American Geophysical Union.

Paper number 96JA02872.

0148-0227/97/96JA-02872\$09.00
}

flection height of the waves. When the ionosphere is perturbed at this height, the waveguide mode structure of the signal tends to change such that its amplitude and phase at the receiver are altered. In this paper we report on a type of signal variation called the "zigzag effect," which frequently appears on VLF/LF propagation paths extending from lower latitudes to the $L=4-$ 5 range and is characterized by quasi-periodic fluctuations with periods that are usually in the $\sim 5-60 \mathrm{~s}$ range. On amplitude versus time records these fluctuations often exhibit a roughly triangular or zigzag shape, but on occasion they appear as negative or positive pulsations that develop substantially faster than they recover.

Figure 1 shows an elegant example of the effect as it appeared simultaneously on the amplitudes of LF signals at 48.5 and $37.2 \mathrm{kHz}$ and on VLF signals from NAA at $24.0 \mathrm{kHz}$ and NSS at $21.4 \mathrm{kHz}$. The map of Figure $2 \mathrm{~b}$ shows the great circle paths of the signals as they extended generally poleward to Siple, Antarctica (SI), at $L \sim 4.3$. Also shown on the Siple analog chart record are (1) (fifth trace) a single channel of magnetic pulsation data from a University of New Hampshire/ University of Minnesota system, (2) (sixth trace) a 2-4 $\mathrm{kHz}$ VLF frequency channel, and (3) (bottom trace) the output of a University of Maryland 20.5- $\mathrm{MHz}$ riometer. VLF/LF signal pulsations with similar rise and decay times began at $\sim 1014$ UT ( 0500 MLT) and terminated 


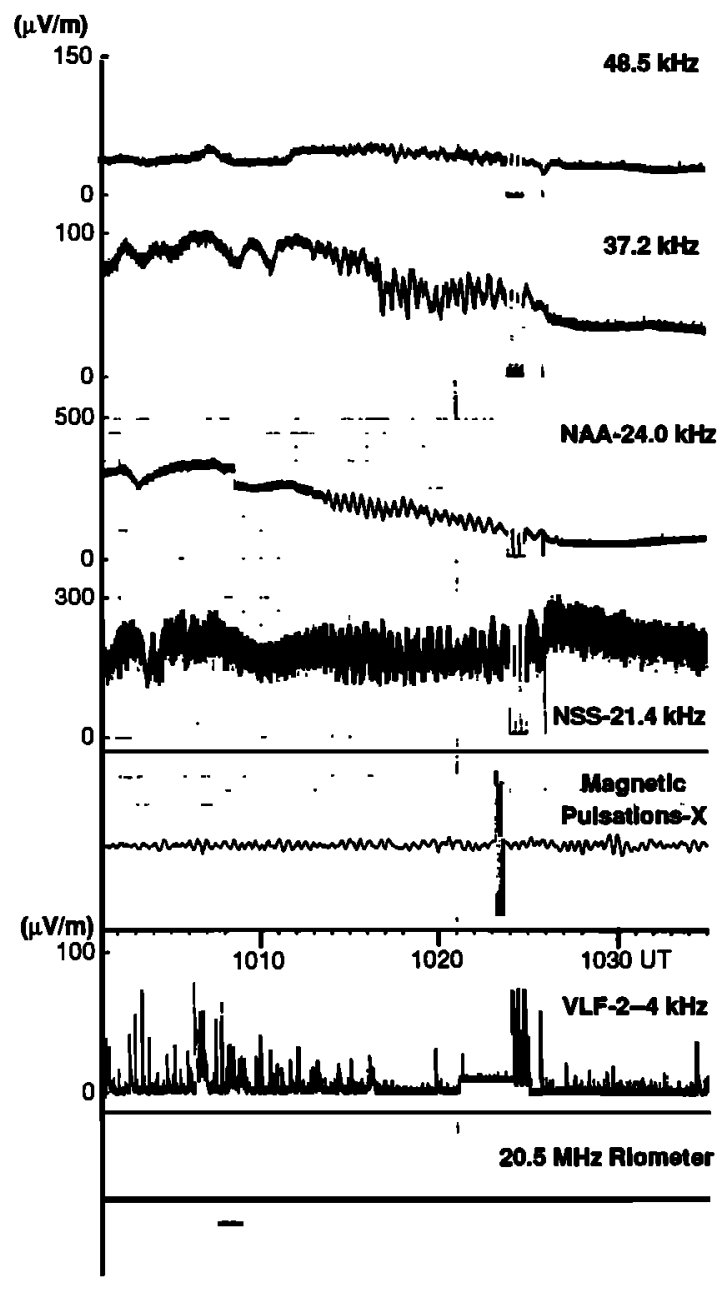

Figure 1. Section of an analog correlation chart from Siple Station, Antarctica, on August 25, 1986, showing a particularly clear example of simultaneous symmetrical zigzag activity beginning at 1014 UT on multiple VLF/LF subionospherically propagating signals.

abruptly $\sim 12 \mathrm{~min}$ later at $1026 \mathrm{UT}$ (the interruption on the LF/VLF channels at 1024-25 UT was caused by operation of the experimental VLF transmitter at Siple). Adjacent extrema were separated by $\sim 30 \mathrm{~s}$ during most of the event.

Why has this apparently well defined VLF/LF phenomenon not been reported previously? The delay is partly a result of problems in recognizing the effect against the generally noisy and poorly understood signal backgrounds characteristic of subauroral regions. Recognition has also been complicated by substantial variability in the period of the fluctuations and in the pulsation envelope shapes. Studies actually began with unpublished research notes by C. Park on VLF subionospheric signal data recorded in 1975 at Siple, Antarctica. A 1984-1985 survey of Siple records for 1982 and 1983 revealed numerous examples of zigzag effects, and a report on the phenomenon was made at the 1985 AGU Spring Meeting [Carpenter et al., 1985a]. Later, corroborating evidence of zigzag effects was found in recordings of signals from NSS and NAA at Halley, Antarctica ( $L \sim 4.2$ ) [Clark, 1991]. One of us (M.G., unpublished report, 1992) studied the effect in northern hemisphere recordings at Saskatoon, Canada $(L \sim 4.2)$, and most recently, Corcuff [1996] reported the occurrence of zigzag-like fluctuations as well as trains of fast-rise, slow-decay pulsations in the amplitude of NWC signals $(22.3 \mathrm{kHz}$, Northwest Cape, Australia, $L \sim 1.4)$ received under magnetically disturbed conditions at Kerguelen Island $\left(49.5^{\circ} \mathrm{S}, 70.2^{\circ} \mathrm{E}, L \sim 3.7\right)$.

Is the zigzag effect evidence at VLF of an already well known phenomenon in which radio signals probing the ionosphere at medium frequencies and above are found to fluctuate with periods in the range from $\sim 10 \mathrm{~s}$ to several minutes, often during periods when ground magnetometers reveal fluctuations of similar period [e.g., Tedd et al., 1989; Sutcliffe and Poole, 1989, and references therein]? The radio measurements have included frequency shifts of ionospherically reflected waves [e.g., Chan et al., 1962; Rishbeth and Garriott, 1964; Davies and Baker, 1966; Sutcliffe and Poole, 1984; Jarvis and Gough, 1988; Tedd et al., 1989], fluctuations in total electron content (TEC) [Davies and Hartmann, 1976; Okuzawa and Davies, 1981], ion drifts detected by incoherent scatter radar [Lathuillere et al., 1981; Glangeaud et al., 1985], and changes in virtual height of a middlelatitude sporadic $E$ layer [Devlin et al., 1977]. As noted below, there are substantial differences in occurrence between some of these observations and the zigzag effect, but geophysical links between the VLF activity and some of the higher-frequency effects may nevertheless exist.

Is the zigzag effect a manifestation of the Trimpi effect, in which fast developing $(\sim 1 \mathrm{~s})$, slow recovering $(\sim 30 \mathrm{~s})$ amplitude or phase perturbations on subionospheric signals occur as a result of scattering of bursts of electrons of energy $E>40 \mathrm{keV}$ into the ionospheric loss cone, the scattering being induced by magnetospherically propagating whistler mode waves [e.g., Helliwell et al., 1973; Rycroft, 1973; Voss et al., 1984; Inan and Carpenter, 1986; Burgess and Inan, 1993; Corcuff, 1996]? As discussed below, we believe that a subset of zigzags is attributable to a Trimpi-like process, at least in the sense of being induced by precipitating $E>40 \mathrm{keV}$ electrons. The classic Trimpi effect is observed in one-toone association with whistlers propagating within the plasmasphere, predominantly in the $L \sim 2-3$ range. The signal perturbations usually appear with irregular spacings and against relatively quiet backgrounds. VLF signal perturbations induced by wave-associated burst precipitation poleward of the plasmapause have also been investigated, but not in as much detail. Examples thus far reported include one-to-one correlations with whistlers and whistler-triggered VLF chorus emissions as well as with individual hiss and chorus events [Dingle and Carpenter, 1981; Carpenter et al., 1985b; Hurren et al., 1986; Corcuff, 1996]. The zigzag effect also appears to be induced by ionospheric disturbances poleward of the plasmapause, but in contrast to the 'normal' Trimpi effect has proven difficult to associate on a one-to-one basis with other geophysical activity, including magnetospherically propagating VLF waves. Note, for example, in Figure 1 that significant changes do not appear on the magnetic pulsation, $2-4 \mathrm{kHz} \mathrm{VLF}$, or riometer channels at the start and stop times of the zigzag event (a horizontal mark below the riometer trace indicates its level during the last previous peak in absorption at $0850 \mathrm{UT}, \sim 11 / 2$ hours earlier, when there was $\sim 1.5$ $\mathrm{dB}$ more absorption than is indicated in Figure 1).

Could subionospheric signal fluctuations such as those illustrated in Figure 1 be induced by the modulated 
electron fluxes associated with pulsating aurora? We believe that this is the case but as discussed below are confronted with several competing explanations of the manner in which the energy of precipitation is transformed into ionospheric changes at the VLF reflection height.

\section{Sources of Data and Methods of Analysis}

Subionospheric VLF signal data from Siple, Antarctica, and Saskatoon, Canada, were examined. Limited data sets from Palmer and Halley, Antarctica, and from northern hemisphere stations Stanford, California and Lake Mistissini, Quebec were also investigated. Figure 2a shows on a northern hemisphere map signal paths from transmitters NPM, NLK, $48.5 \mathrm{kHz}$, NSS, NAA, and NAU (circles) to receivers at Saskatoon (SA), Stanford (SU), and Lake Mistissini (LM) (squares). Figure $2 \mathrm{~b}$ shows on a southern hemisphere map receiver locations at Siple (SI), Palmer (PA), and Halley (HB), Antarctica, as well as the great circle paths of a number of VLF/LF signals of interest.
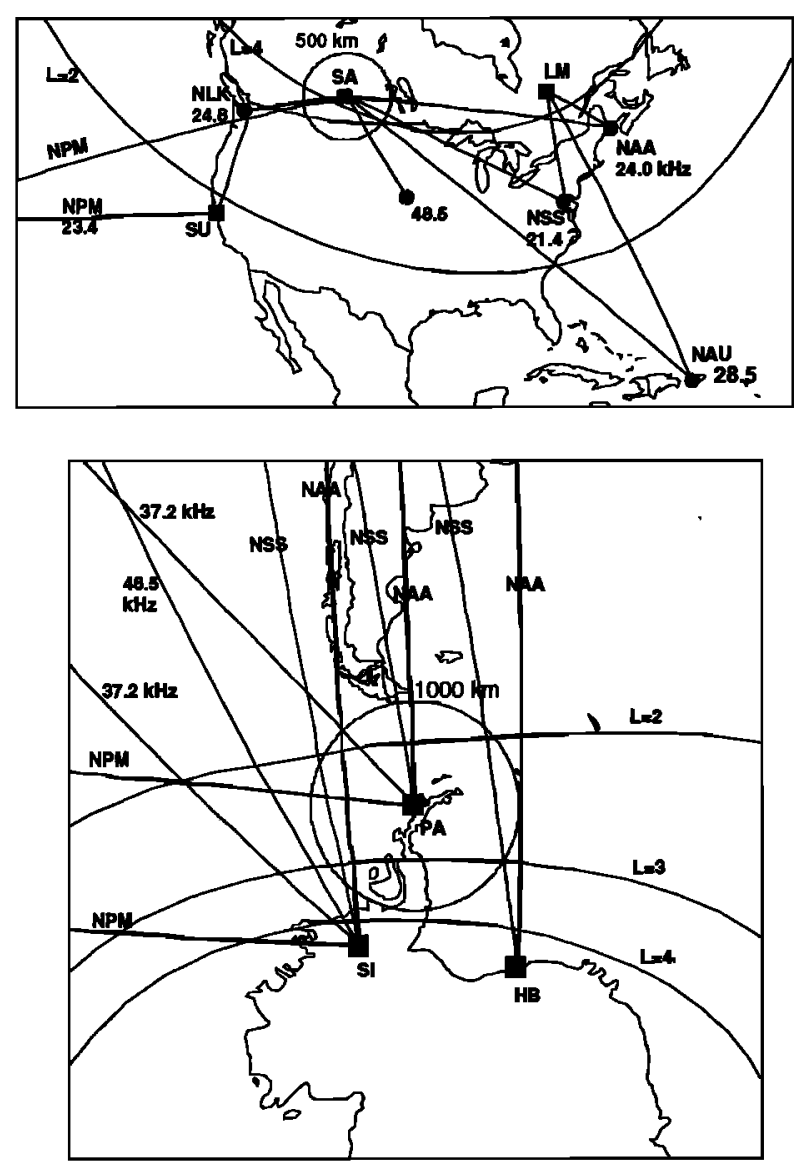

b)

Figure 2. (a) Map showing a variety of subionospheric VLF/LF signal paths from northern hemisphere transmitters to receiver locations at Stanford, California (SU), Saskatoon, Canada (SA), and Lake Mistissini, Canada (LM). (b) Map showing the locations of Siple (SI), Palmer (PA), and Halley (HB) Stations, Antarctica, and the great circle paths of several VLF/LF signals received at those locations.
The Siple records initially studied, from 1982,1983 , and 1986, were 24-hour analog charts (the 1986 data were later supplemented by $10-\mathrm{Hz}$ digital recordings of outputs from multiple Siple instruments by a University of Maryland logging system). The Saskatoon study involved digital recordings of signal amplitude; data from March 1988 and February and March 1989 were chosen because of a favorable combination of high geomagnetic activity and relatively long periods of darkness along the signal paths of interest. Daily summary charts generated in the field were first inspected for activity, and periods of interest were then examined using special display software.

\section{Experimental Results}

There were similarities as well as differences in the zigzag activity observed at Siple and at Saskatoon, the locations receiving special attention in our study. Because of the differences the results will first be summarized according to receiver location.

For convenience we will use the term zigzag effects throughout to denote the occurrence of trains of pulsations in VLF signal amplitude with periods in the 5-100 s range. Note, however, that there was much variation from time to time and station to station in the detailed amplitude-time shape of the pulsations.

\subsection{Siple Station}

3.1.1. Occurrence properties of the zigzag phenomenon. The first work on zigzag effects at Siple was based upon visual inspection of analog chart records. Identifiable zigzag activity was often episodic and on occasion was characterized by abrupt, clear onsets and terminations of activity, as illustrated in Figure 1. However, fluctuation activity with period $<1 \mathrm{~min}$ was usually more complex than Figure 1 suggests; this is illustrated in Figure 3, which shows a 3-hour record of NAA and NSS at Siple from 1982. Relatively clear episodes of zigzag activity on NAA and NSS could be seen in the intervals $\sim 0742-0752$ UT and $\sim 0850-0900$ UT (the effect was better defined on the NAA signal because of differences in the processing of the two signals by the separate NAA and NSS receivers). Also recognizable as zigzag events were the lower-amplitude activity from $\sim 0732$ to $\sim 0742$, the several minute burst of faster fluctuations near 0755, and two short trains of oscillations near 0933 UT. Other fluctuations on the records with periods $\sim 1 \mathrm{~min}$, such as those between 0700 and 0720 , were not classified as zigzags because of their lack of appearance in trains of similar changes.

In spite of the limitations imposed by the relatively compressed nature of the chart records, certain occurrence properties of the zigzag effect at Siple were determined by noting the approximate fluctuation period, event duration, and local time of occurrence of episodes such as those illustrated in Figures 1 and 3 . In a study of Siple charts from June and July 1982, events were found on 11 of 30 days in June and 13 of 31 days in July. The fluctuation periods were mostly in the 1020 s range, although periods as long as $\sim 2 \mathrm{~min}$ were sometimes observed. Seventy four episodes were identified, or an average of about 3 per day of activity. Almost half of the 74 events were between 10 and $20 \mathrm{~min}$ in duration and only six were found in the 60 to 90 min range. Episodes occurred within 59 one-hour peri- 


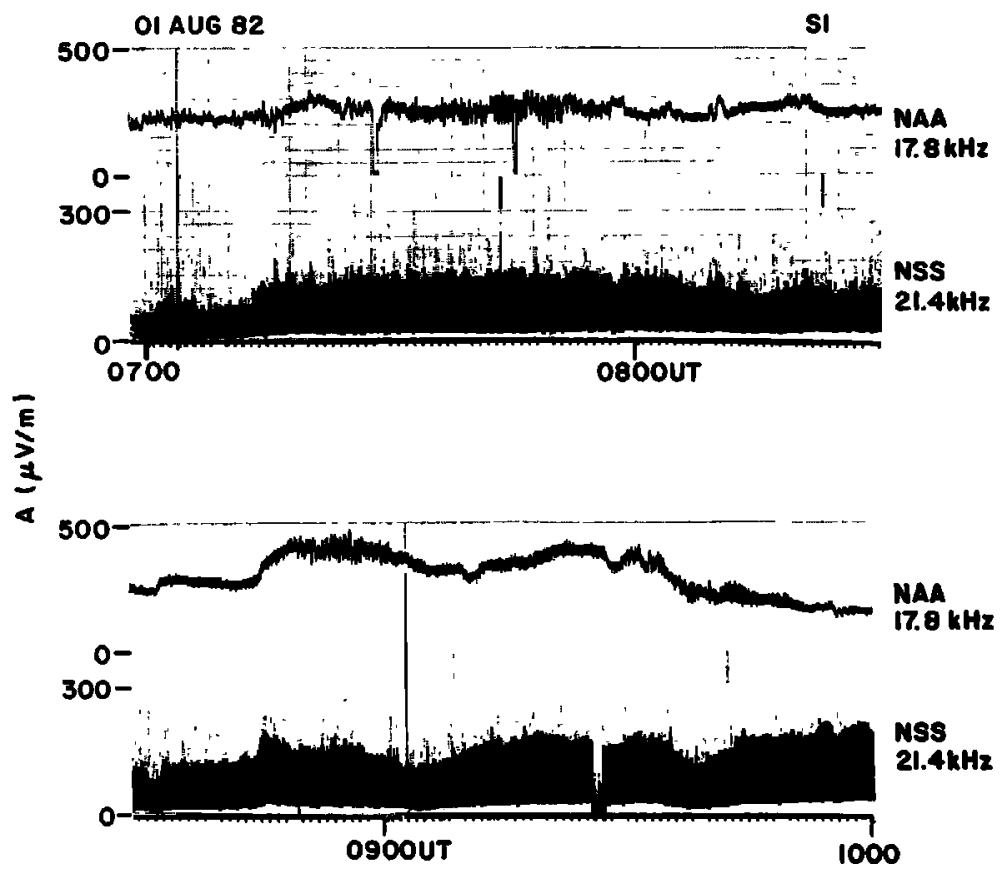

Figure 3. Copies of analog charts from Siple Station showing episodes of zigzag activity on the amplitude of NAA and NSS during a 3-hour period.

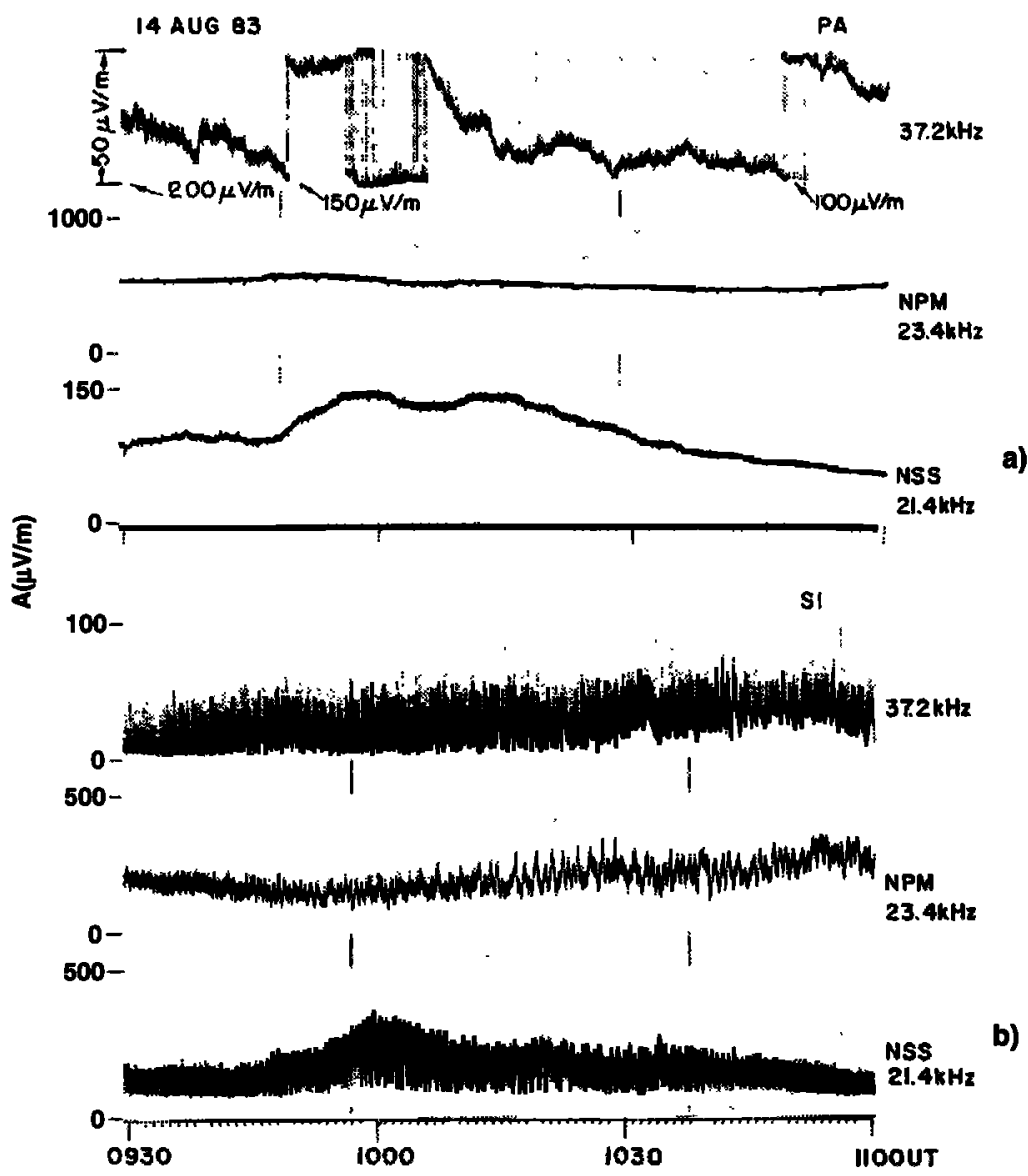

Figure 4. Comparison of Palmer and Siple analog charts during a 1 1/2-hour period when zigzag activity was detected at Siple and whistler-induced precipitation (Trimpi events) occurred at Palmer. (a) Palmer records showing the amplitude of NPM, NSS, and a signal at $37.2 \mathrm{kHz}$ from California. (b) Siple records for the same three signals (see map of Figure 2b). 
ods, all but two being after midnight, with half in the predawn hours between 0800 and 1000 UT ( 0300 and 0500 MLT).

At Siple zigzag fluctuation amplitudes represented variations of from $\sim 10 \%$ to $\sim 70 \%$ of average levels, somewhat larger than the $\sim 5 \%-20 \%$ perturbations in typical Trimpi events [e.g., Inan and Carpenter, 1986]. The amplitudes on the closely spaced NSS and NAA paths (see map of Figure $2 \mathrm{~b}$ ) were usually comparable, as illustrated in Figures 1 and 3 (note differences in the NSS and NAA amplitude scales).

Some information on the spatial location and distribution of the ionospheric disturbances giving rise to zigzag effects can be obtained by considering the location of affected signal paths and by comparing signal path data from spaced stations such as Siple and Palmer, Antarctica (see map of Figure 2b). During the month of August 1983, amplitudes of signals $37.2 \mathrm{kHz}$, NPM, and NSS were recorded on analog charts at both locations. In the Palmer data zigzag activity was not evident, while in the Siple records it appeared during several of the more geomagnetically active periods. Figures $4 \mathrm{a}$ and $4 \mathrm{~b}$ show the Palmer and Siple, respectively, data on an occasion when well defined zigzags appeared at Siple near 0500 MLT. The activity lasted for an hour or more, substantially longer than the episodes illustrated in Figures 1 and 3. Zigzags continued on NSS for an hour until $1045 \mathrm{UT}$ and until still later on 37.2 $\mathrm{kHz}$ and NPM because of their more westerly positions with respect to the sunrise terminator (see map of Figure 2b). Meanwhile, at Palmer and on the same set of signals (top three traces), zigzag activity could not be identified. Ionospheric perturbations due to whistler scattering (Trimpi effects) were occurring, as indicated on the Palmer NPM signal by small negative perturbations, particularly between $\sim 0945$ and $\sim 1015$ UT. Prolonged Trimpi activity was observed on one or more of the three signals at Palmer on several of the nights when zigzags were detected at Siple. It appeared that while the mechanism of the zigzag effect could affect Siple signals and could do so over a wide range of signal azimuths, at Palmer it was either masked by the Trimpi effect or (the more likely alternative) was restricted in its action to an $L$ range poleward of the station. That the latter was true is suggested by a visual examination of several weeks of Palmer digital survey charts from 1989, 1990, and 1991. Zigzag effects were found in only one period, in the aftermath of a severe magnetic storm when $K p$ reached a value of 8 .

3.1.2. Examples of correlated geophysical activity. Zigzag activity at Siple was found to occur exclusively when the station was poleward of the ionospheric projection of the plasmapause and when substorm activity was at moderate levels or higher as indicated by $K p$ index levels in the 2-4 range and above. In a typical case, evidence of precipitation into the overlying ionosphere, sometimes pulsating in nature, appeared near or shortly after midnight and the zigzag activity appeared later, when clear evidence of the overhead precipitation was no longer present. Figures 5 and 6 illustrate such a case, from September 14, 1986. They display (top to bottom) the outputs of (1) Stanford narrowband NSS and NAA receivers, (2) a $2-4 \mathrm{kHz}$ filter connected to the Stanford broadband VLF receiver, (3) a Lockheed vertical looking photometer at $427.8 \mathrm{~nm}$ with a field of view $<30^{\circ},(4)$ the $X$ component of a University of New Hampshire/University of Minnesota

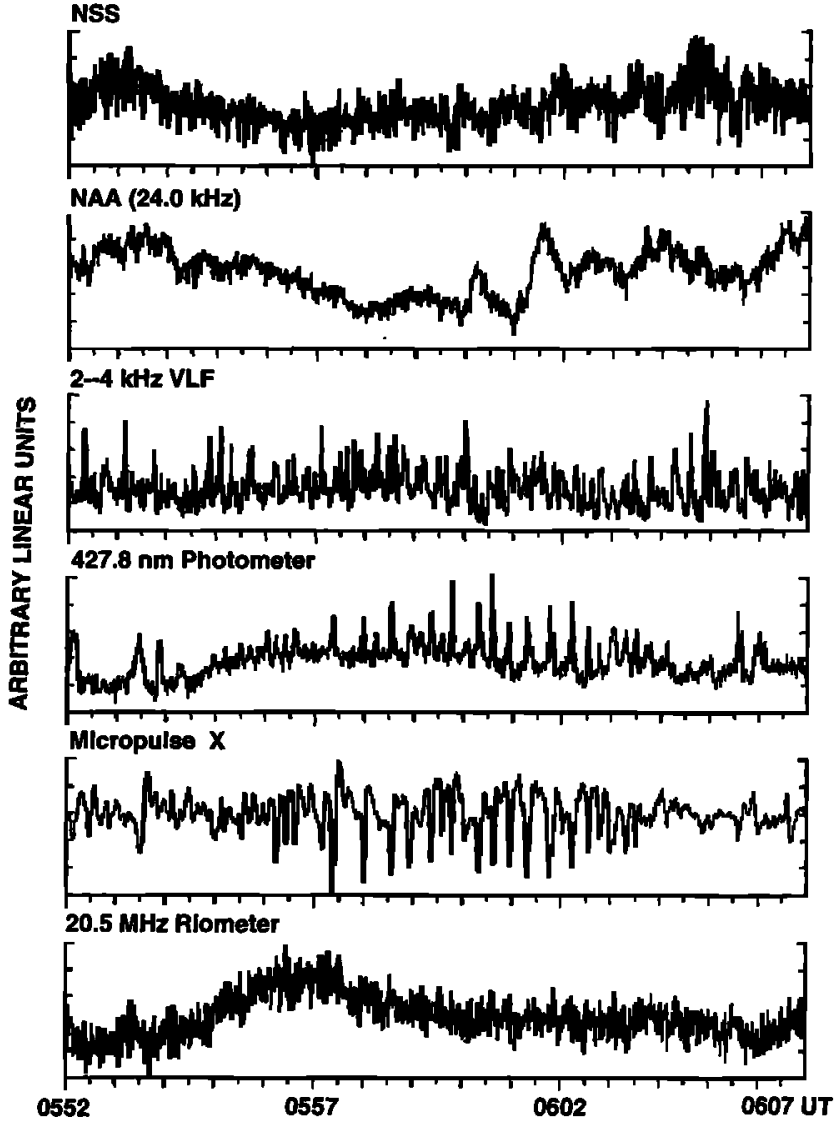

Figure 5. Digitally logged data from multiple Siple instruments on September 14, 1986 (day 257), illustrating a period of pulsating auroral activity overhead the station. In order from top to bottom are outputs of Stanford narrowband VLF receivers (NSS, $21.4 \mathrm{kHz}, \mathrm{NAA}$, $24.0 \mathrm{kHz}$ ), a $2-4 \mathrm{kHz}$ filter connected to the Stanford broadband VLF receiving system, a Lockheed 427.8$\mathrm{nm}$ vertical looking photometer, a University of New Hampshire/University of Minnesota search coil magnetometer ( $X$ component), and a University of Maryland 20.5- $\mathrm{MHz}$ riometer. The amplitude range displayed for each quantity is chosen so as to utilize the full vertical extent of each trace while not truncating the data.

search coil magnetometer, and (5) a University of Maryland $20.5-\mathrm{MHz}$ riometer with a $\sim 60^{\circ}$ field of view. On each panel the amplitude range has been adjusted to achieve optimum sensitivity within the time interval displayed.

Figure 5 represents a $15-\mathrm{min}$ period around 0600 UT (0100 MLT) and Figure 6 a similar period $\sim 2$ hours later. In Figure 5 the NSS and NAA amplitudes exhibited irregular variations characteristic of nighttime at middle latitudes under disturbed conditions, but there were no clear zigzag effects. Between $\sim 0556$ and $\sim 0604$ UT, the Lockheed vertical looking photometer (fourth trace) detected pulsations at intervals varying irregularly from $\sim 15$ to $40 \mathrm{~s}$. These changes were matched one to one with magnetic pulsations, as indicated on the fifth trace by the search coil magnetometer. In other work [e.g., Arnoldy et al., 1982; Oguti et al., 1984] such "one-sided" magnetic pulsations have been identified as Pil activity and attributed to precipitation-induced increases in ionospheric conductivity and in associated 


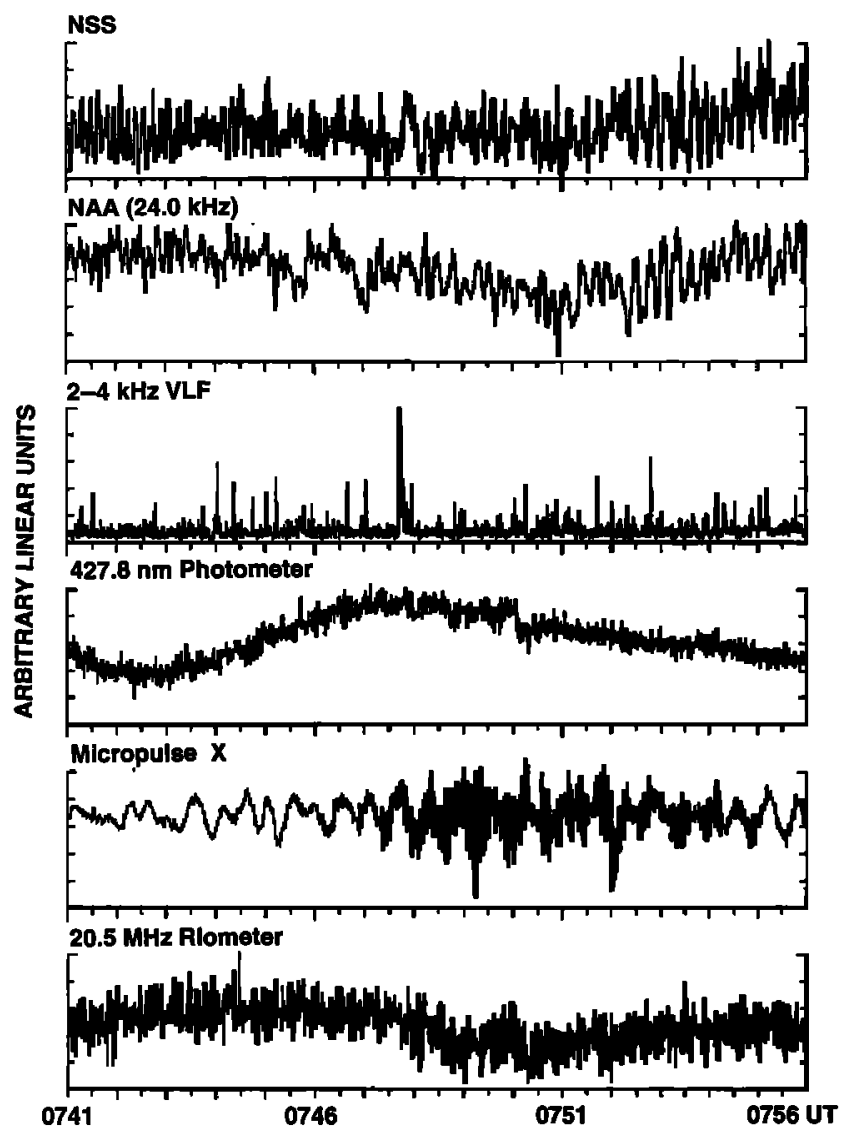

Figure 6. Siple multi-instrument record, in the format of Figure 5, but showing a period of zigzag activity on NSS and NAA $\sim 2$ hours after the pulsating auroral activity shown in Figure 5.

ionospheric currents. The riometer (sixth trace) did not show clear evidence of pulsations. Most likely, the precipitation-induced changes in radiowave absorption associated with the optical bursts covered a relatively small fraction of the riometer's $\sim 60^{\circ}$ field of view and thus were too small to be detected by this broadbeam instrument.

The 2-4 $\mathrm{kHz}$ VLF channel (third trace) showed irregular burst activity produced by VLF chorus. In other studies, one-to-one correlations have been found between sequences of VLF chorus bursts, propagating poleward of the plasmapause, and trains of pulsations registered by $\mathrm{X}$ ray detectors or photometers [e.g., Rosenberg et al., 1971; Helliwell et al., 1980]. However, in this case the $2-4 \mathrm{kHz}$ changes were not correlated on a one-to-one basis with the optical bursts. Their more complex temporal structure is attributed to the large magnetospheric viewing area of the VLF receiving system, of order $500 \mathrm{~km}$ in radius around the station at ionospheric heights. The received VLF spectrum probably included chorus elements whose magnetospheric path endpoints were well outside the view of the photometer.

Figure 6, for the period near 0800 UT (0300 MLT), shows strong zigzags on both NSS and NAA, with quasiperiod $\sim 10 \mathrm{~s}$ between the beginning of the record and $\sim 0745 \mathrm{UT}$ and $\sim 15 \mathrm{~s}$ between $\sim 0748 \mathrm{UT}$ and the end of the record. At this time there was no clear evidence of overhead auroral pulsations at $427.8 \mathrm{~nm}$ (fourth trace).
The magnetic pulsation detector (fifth trace) exhibited a background of low-amplitude Pc 3 pulsations with period $\sim 40 \mathrm{~s}$ on which Pc 1 activity was superposed between $\sim 0741$ and $\sim 0755$ UT (note the difference in scales between Figures 5 and 6 ). However, no one-sided Pi 1 pulsations were now evident. Again, the riometer showed no well-defined pulsation activity and the 2-4 $\mathrm{kHz}$ VLF (third panel) was much quieter than in the earlier period.

\subsection{Halley, Antarctica}

Several examples of zigzag activity on NSS and NAA as received at Halley in 1988 were found by one of us (T.D.G.C.) in a recent study [Clark, 1991]. As at Siple the events were concentrated in the predawn hours. Figure 7 illustrates a portion of the best documented case. It shows the amplitudes of signals from NSS and NAA as well as two signals from the British Isles, GBZ (19.6 $\mathrm{kHz})$ and GQD (19.0 kHz) during the period 0505-0530 UT on July 26,1988 . These signals were recorded on magnetic tape, and to remove any amplitude fluctuation caused by tape reel rotation, the signals were lowpass filtered with a cutoff period of $10 \mathrm{~s}$. A cross spectral analysis revealed that the $\sim 20$-s fluctuations in the two British signals were in phase with each other and approximately $180^{\circ}$ out of phase with the fluctuations on NSS. The latter were approximately $90^{\circ}-120^{\circ}$ out of phase with those from NAA. However, during a further burst of zigzag activity between 0700 and $0730 \mathrm{UT}$, variations in the NSS and NAA signals were approximately in phase (the amplitudes of the British signals had decreased to the noise level at this time). Although there was VLF emission activity (1.5-2.5 kHz) and ULF pulsation activity observed at Halley around the same time, cross-spectral analysis revealed no significant coherence between the zigzag activity on the transmitter signals and either of these two phenomena.

\subsection{Saskatoon}

3.3.1. Appearance of zigzag effects in daily survey records. In 1992 a study was made of Saskatoon data from two geomagnetically active months,

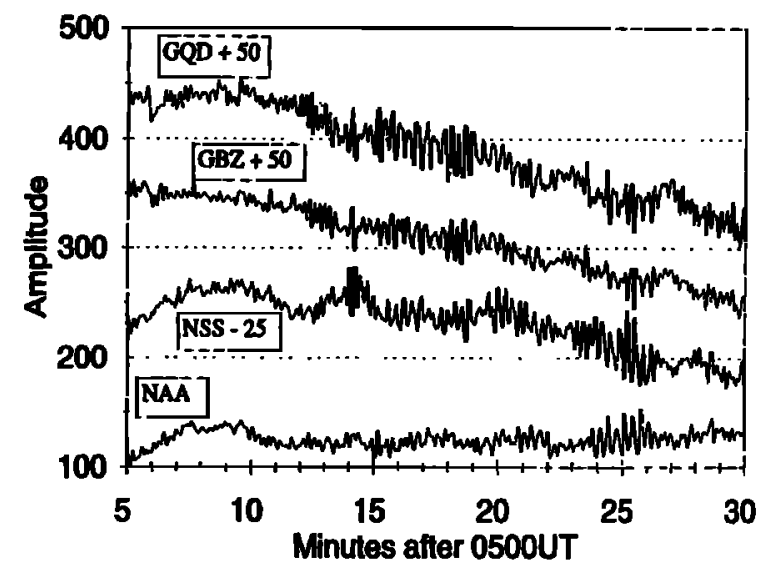

Figure 7. Amplitudes of four transmitter signals received at Halley on July 26, 1988 between 0505-0530 UT. The amplitude scale is an uncalibrated linear scale, and three of the signals have had offsets applied to them, as indicated in the labels, to separate the traces in the plot. 


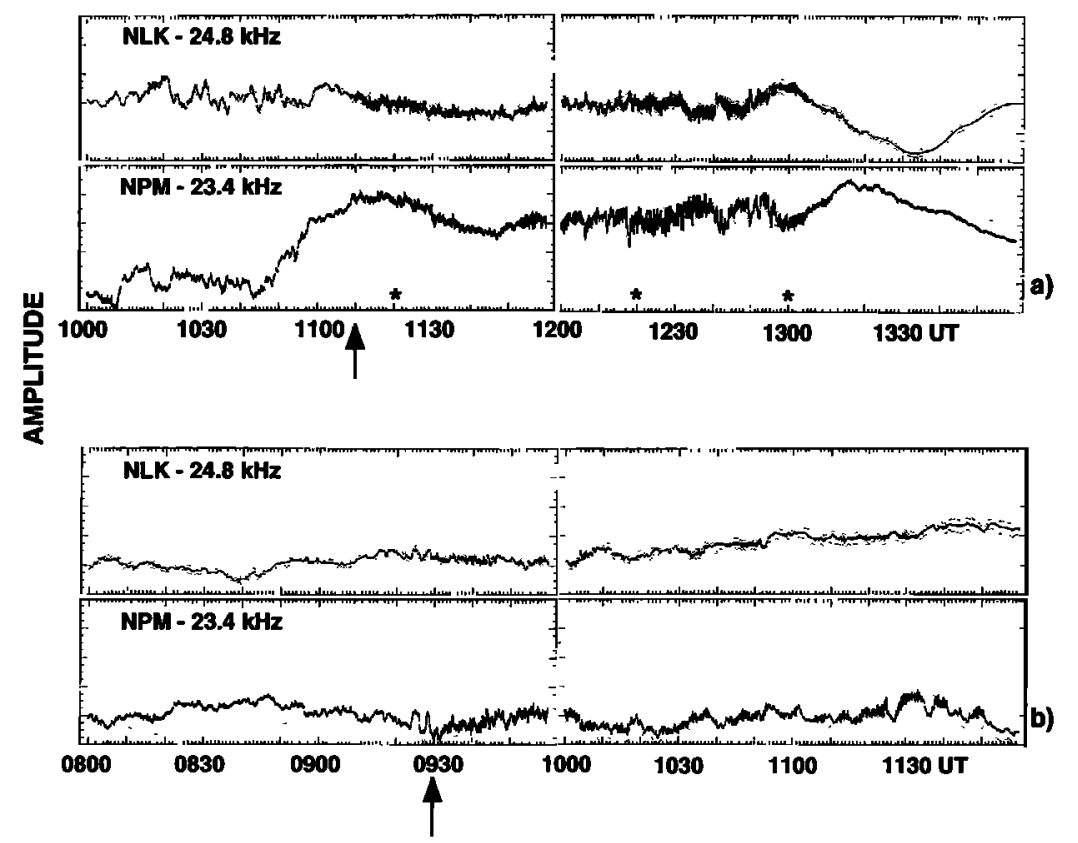

Figure 8. (a) Section of the daily summary chart of signals NLK and NPM at Saskatoon on March 8, 1988, illustrating the occurrence of a multihour interval of enhanced fluctuation activity. An arrow marks the begining of the interval and asterisks mark the times of activity samples shown in Figures 9, 10, and 11. (b) Same for March 4, 1988.

March 1988 and March 1989. Two days, March 4 and 8, 1988 , were examined in detail, while others were studied either from the survey charts or by means of limited reprocessing. It was found that zigzag activity, often in the $\sim 10-30$ s period range but sometimes with periods approaching $100 \mathrm{~s}$, was a common feature of periods of "fast" fluctuations that tended to begin abruptly and last for several hours. Within such multihour periods there were substantial variations in the quasi-period and amplitude envelope of the pulsations. Figures 8a and $8 \mathrm{~b}$ show how such periods appeared on the survey charts of March 8 and March 4, 1988, respectively, for the nearly collinear paths NLK and NPM (see map of Figure 2a). Each chart displays approximately 4 hours of the 8-s average amplitude (uncalibrated) of a signal channel sampled at $50 \mathrm{~Hz}$ (the maximum and minimum values within each $8 \mathrm{~s}$ are also plotted). On March 8 , 1988 , the onset of fast fluctuations was at $\sim 1110 \mathrm{UT}$ or $\sim 0410$ MLT (arrow), while on March 4, 1988, it occurred at $\sim 0930$ UT or $\sim 0230$ MLT.

In the Saskatoon data, periods of fast fluctuations appeared more frequently and at higher average amplitude on NLK and NPM, signals propagating generally west to east (see map of Figure 2a), than on the eastto-west propagating NAA and NSS signals. A $48.5-\mathrm{kHz}$ signal from a source south of Saskatoon often showed zigzag effects, while the NAU signal from Puerto Rico exhibited only a few cases of what appeared to be zigzag activity. Accordingly, the NLK and NPM data and occasionally those of $48.5 \mathrm{kHz}$ were selected for most of the studies involving digital reprocessing and display. As might be expected from the closeness of their great circle paths, the fluctuations on NLK and NPM were often highly correlated, while detailed correlations between $48.5 \mathrm{kHz}$ and those two signals were unusual.

3.3.2. Case studies. Our case study of the $\sim 2$ hour period of fast fluctuations on March 8, 1988, is illustrated in Figures 9, 10, and 11, which show 1.5-
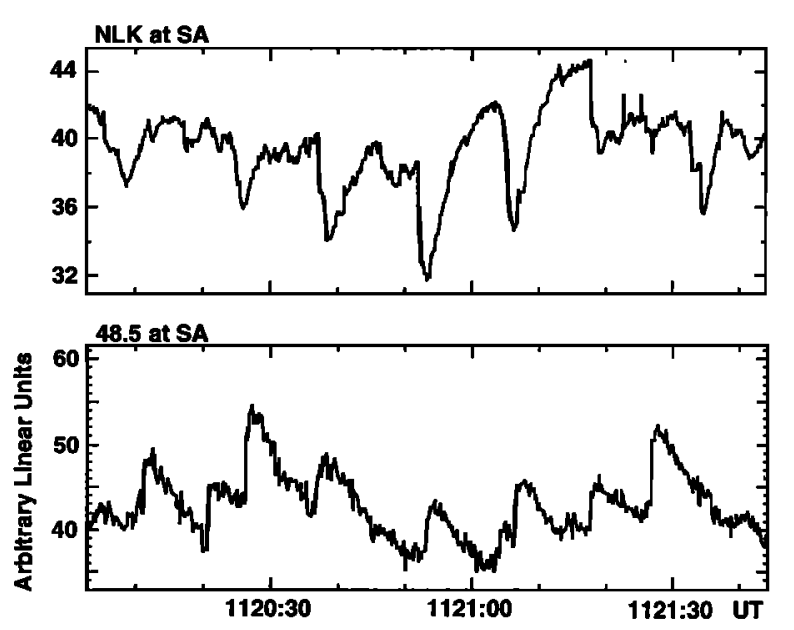

(a)

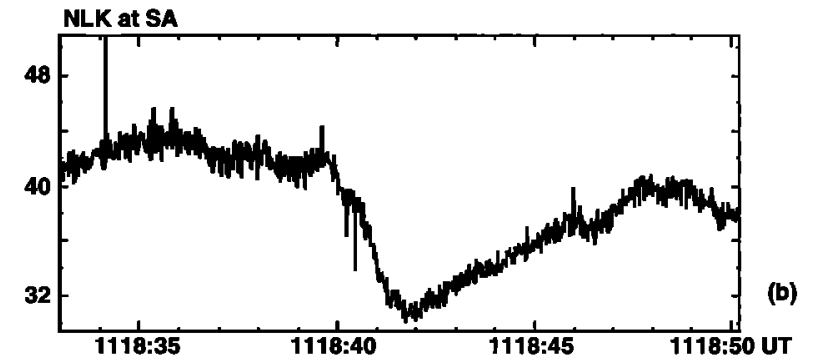

Figure 9. (a) Time-expanded chart of NLK and 48.5 $\mathrm{kHz}$ for a $\sim 1.5 \mathrm{~min}$ interval beginning $\sim 10 \mathrm{~min}$ after the onset on March 8, 1988, shown in Figure 8a. The shape of the pulsations, with fast rise and slow decay, resembles that of pulsations known to be associated with bursts of precipitating electrons (e.g., Trimpi effects). b) Expanded record of a single event on NLK detected shortly after the onset. 

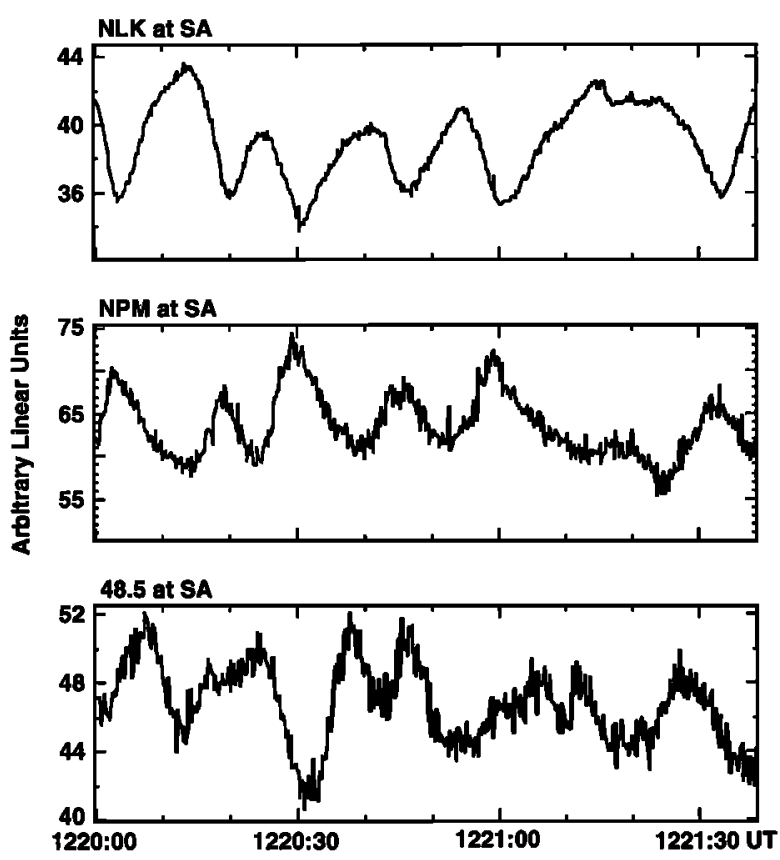

Figure 10. Saskatoon data on NLK, NPM, and 48.5 $\mathrm{kHz}$ from a period near $1220 \mathrm{UT}$ on March 8, 1988, an hour following the activity shown in Figure 9. At this time the NLK and $48.5 \mathrm{kHz}$ signals were no longer closely correlated.

min samples of zigzag activity at the times indicated in Figure $8 \mathrm{a}$ by asterisks. Figure $9 \mathrm{a}$ shows activity on NLK and $48.5 \mathrm{kHz}$ at $1120 \mathrm{UT}, \sim 10 \mathrm{~min}$ after the onset of fast fluctuations. This is a rare instance in which there was a clear antiphase relation between the NLK and $48.5-\mathrm{kHz}$ signals in spite of their widely different arrival bearings (map of Figure 2a). At this time the mean interval between pulses was $\sim 10 \mathrm{~s}$, and the fluctuations were clearly not zigzag-like or triangular in shape. Instead, they had fast developments and slower recoveries, as do signal changes previously found to be associated with bursts of precipitating electrons that create secondary ionization patches at $\sim 85 \mathrm{~km}$ altitude (e.g., Trimpi effects). The development times were found to vary between $\sim 0.4$ and $2.5 \mathrm{~s}$ and the recovery times between $\sim 4$ and $8 \mathrm{~s}$, the latter being substantially shorter than the recovery times commonly observed when Trimpi effects occur within the plasmasphere. Similar pulsations on a signal path from NWC (Australia) to Kerguelen $\left(49.5^{\circ} \mathrm{S}, 70.2^{\circ} \mathrm{E}, L=3.7\right)$ were found by Corcuff [1996] in the aftermath of severe magnetic storms. Figure $9 \mathrm{~b}$ shows a single event on NLK in which an amplitude decrease took place over $\sim 2 \mathrm{~s}$ and the recovery over $\sim 6$ s.

Within 1 hour following the activity of Figure 9 the shape of the pulsations had become more symmetrical about the narrower peaks or minima, and the mean interpulsation period had increased to between 12 and 15 s. Figure 10 shows activity near 1220 UT on NLK, NPM, and $48.5 \mathrm{kHz}$. On NLK and NPM the recovery time was noticeably longer than the development time but only by a factor of about 2 at most. NLK and NPM were approximately opposite in phase; a crosscovariance analysis provided a 0.2 -s time lag for anticorrelation, while direct measurement showed NLK minima lagging the nearest NPM maxima by $\sim 0.5-1 \mathrm{~s}$.
The $48.5-\mathrm{kHz}$ and NLK signals were no longer closely correlated, as they had been an hour earlier. Zigzags were clearly present on $48.5 \mathrm{kHz}$ but with a shorter quasi-period, near $12 \mathrm{~s}$.

Figure 11a shows fluctuations on NLK and NPM at $\sim 1300 \mathrm{UT}, \sim 10 \mathrm{~min}$ prior to their disappearance at sunrise. By this time the quasi-period of the fluctuations had increased to $\sim 20 \mathrm{~s}$, and there was increased symmetry in shape about the minima on NLK and the peaks on NPM. The regularity of the pulsations is suggested in Figure 11b by a spectral analysis for NLK, which shows a strong peak at $\sim 0.05 \mathrm{~Hz}$.

At 1300 UT, NLK and NPM continued to be in approximate antiphase, with NLK again lagging, now by $\sim 1.5 \mathrm{~s}$. The increase in quasi-period from $\sim 15$ to $\sim 20$ $\mathrm{s}$ between 1220 and 1300 UT (Figures 10 and 11) appeared to be accounted for not by an increase in the duration of the individual pulsations but instead by increased delays between pulsations. In this and at least one other case it was noted that the quasi-period of the fluctuations increased to the $20-30 \mathrm{~s}$ range as sunrise approached but then decreased for several minutes as the fluctuation activity began to disappear.

Data from March 4, 1988, the other day analyzed in some detail, are summarized in Figure $8 \mathrm{~b}$ and illustrated in Figure 12. Figure 12a shows a $\sim 25$-min interval around the $\sim 0930$ UT ( 0230 MLT) onset of fast fluctuations, and Figure 12b shows 3 min of expanded NLK and NPM data beginning at the onset. At this time the pulsation activity was irregular, but a quasiperiod of $\sim 10 \mathrm{~s}$ could be identified. In contrast to the case of March 8, 1988, NLK and NPM were approximately in phase, a condition that persisted throughout the interval of fast fluctuations. The shapes of the pulsations varied noticeably from pulse to pulse.

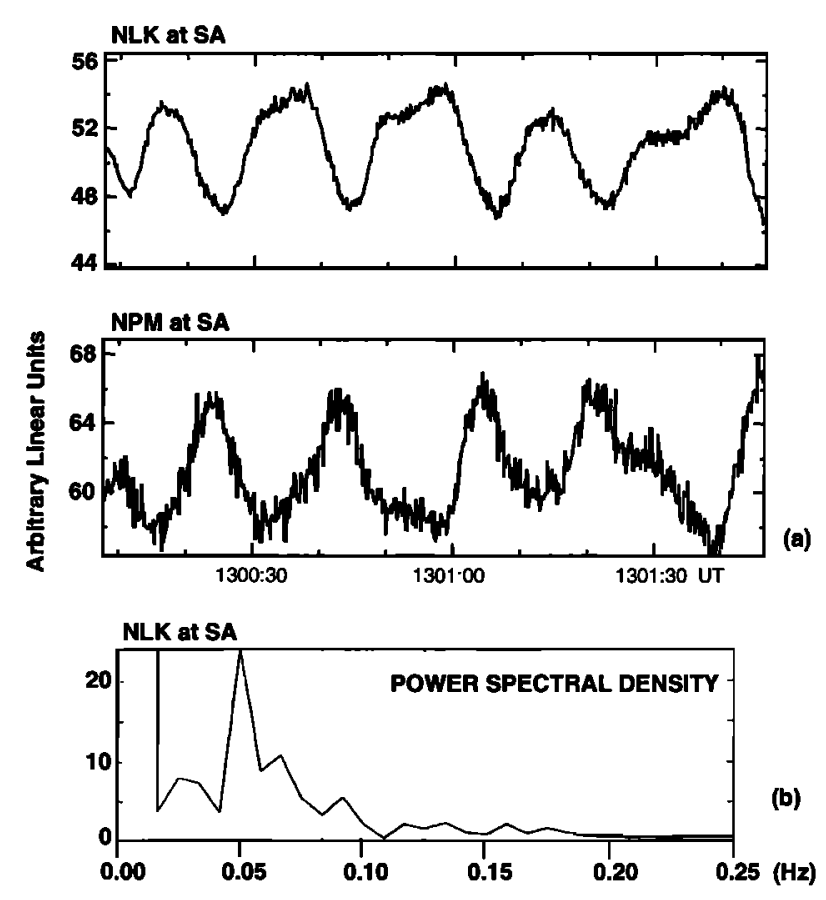

Figure 11. (a) Fluctuations on NLK and NPM at $\sim 1300$ UT on March 8, 1988, 10 min before the decay of activity at sunrise shown in Figure 8a. (b) Spectral analysis of the NLK record between 1300 and 1301:39 UT, showing a strong peak at $\sim 0.05 \mathrm{~Hz}$. 


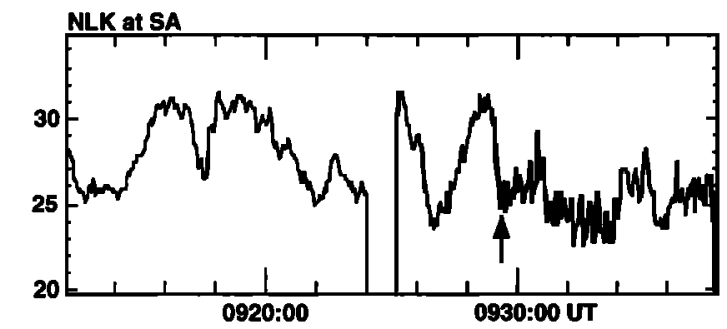

(a)

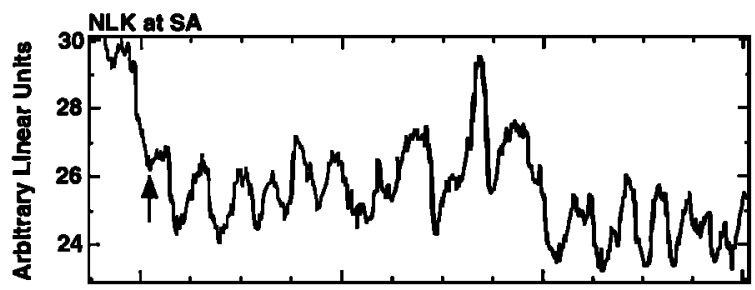

(b)

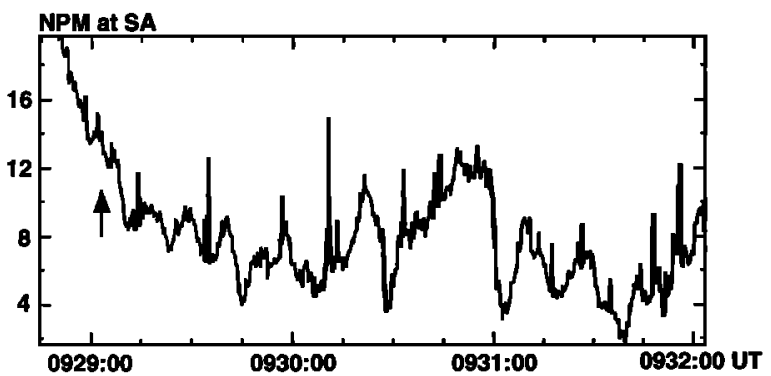

Figure 12. (a) Expanded record near 0920 UT on March 4, 1988, showing the onset of enhanced fluctuations on NLK at Saskatoon (see Figure 8b).(b) Three minutes of NLK and NPM activity immediately following the onset illustrated in Figure 12a. In contrast to the case of March 8 (see Figures 10 and 11), NPM and NLK were approximately in phase.

3.3.3. Zigzag occurrence properties. Activity of the general kind illustrated in Figures 8 through 12 was found on NLK and NPM at Saskatoon on 10 of 25 days studied in March 1988 and on 13 of 31 days in March 1989. As at Siple and Halley, the activity was concentrated in geomagnetically active periods. Most of it occurred when $K p$ was in the range $3-5$; no case was found when $K p$ was $<3$.

The peak-to-peak amplitude of the zigzag fluctuations on NLK and NPM was typically between 10 and $15 \%$ of the mean value of the signal, reaching $50 \%$ of the mean value in several cases. On $48.5 \mathrm{kHz}$ the typical amplitude tended to be somewhat lower and was still lower on NSS and NAA.

The onsets of the multihour episodes containing zigzag activity on NLK and NPM occurred mostly in the range 0900-1130 UT, or 0200-0430 MLT but tended to be earlier on the few days when $K p$ was 5 or greater. The terminations, mostly due to sunrise effects, occurred between 1200 and 1300 UT or $\sim 0500$ and 0600 MLT. The onsets of activity on $48.5 \mathrm{kHz}$ were on average later than those on NLK and NPM and were later still on NAA and NSS. With sunrise affecting these three signal paths before those of NLK and NPM, their zigzag episodes were found to be shorter in duration than those on NLK and NPM.

3.3.4. Correlated geophysical effects. A comparison was made of the output of a magnetometer at
Saskatoon and simultaneous zigzag activity during four nights in March 1989 on which the onset of zigzags was well defined. In all four cases there was evidence that substorm-associated current systems were active during the zigzag activity and that the zigzag onsets coincided either with the general activation of the current systems or with enhancements thereof, particularly as registered in the $D$ component of the magnetic field.

3.3.5. Spaced station comparisons. Some comparisons were made between the data of Saskatoon and corresponding data recorded at the slightly higher latitude of Lake Mistissini and at the lower latitude of Stanford (see map of Figure 2a). Several months of simultaneous survey charts from 1988 were scanned for NLK and NPM at Saskatoon and Stanford. In no case of fast fluctuations (and by inference, zigzag activity) at Saskatoon was such activity seen at Stanford. In view of the above noted comparison of Palmer and Siple data and of the location of the NLK-Stanford signal path, it is inferred that ionospheric disturbance activity at the times of the Saskatoon events was restricted to a latitude range poleward of $L \sim 3$.

On the other hand, fast fluctuations, sometimes burstlike in form, were seen on occasion at Lake Mistissini ( $L \sim 4.7)$ when similar activity appeared at Saskatoon. From a limited study it appeared that a perturbed zone of the ionosphere moved from east to west, appearing earlier at Lake Mistissini by approximately $1 / 2$ hour and disappearing later at Saskatoon.

\section{Discussion}

\subsection{Location and Spatial Extent of the Ionospheric Perturbations}

Our basic sources of information on the locations of the ionospheric perturbations are (1) evidence from the present study that they occur poleward of the plasmapause projection and (2) other studies indicating that while a perturbed ionospheric region involved in producing a detectable Trimpi effect can be located at varying distances (up to $1000 \mathrm{~s}$ of $\mathrm{km}$ ) from the receiver, the perturbed region must be centered within $\sim 100-200$ $\mathrm{km}$ of the affected great circle signal path [e.g., Poulsen et al., 1990, 1993; Inan et al., 1996]. Under the moderately disturbed geomagnetic conditions $(K p \sim 3-4)$ prevailing during much of the observed zigzag activity at Siple and Saskatoon, the post-midnight plasmapause is believed to have been (on average) in the range $L \sim 3.6-$ 4.2 [e.g., Carpenter and Anderson, 1992; Carpenter and Park, 1973]. If we postulate that the perturbed ionospheric regions involved in the zigzag effect were centered within $\sim 100-200 \mathrm{~km}$ of the affected signal paths, we can then infer from considerations of the plasmapause $L$ value and the signal paths shown on the maps of Figure 2 that most of the observed perturbations on NLK/NPM at Saskatoon were induced within $\sim 500 \mathrm{~km}$ of the station and that a similar range was applicable to changes on NSS and NAA at Siple.

Regarding the number of perturbed regions involved in producing the zigzag effect on nearly collinear paths, we suggest that a single perturbed region was often responsible for the observed signal fluctuations. As an example, this appears to have been the case for NLK and NPM on March 8, 1988, at Saskatoon. If two or more independently pulsating regions had been located so as to significantly affect the paths, the fluctuations 
in the subionospheric signals would not have been expected to exhibit the regularity illustrated in Figures 9 , 10 , and 11 , nor would the phase difference between the NLK and NPM pulsations have been expected to remain nearly the same over the 2-hour period of zigzag activity. A single perturbed region is also consistent with the tendency of the NLK-NPM phase difference to be near either $0^{\circ}$ or $180^{\circ}$ in our observations. As a single ionospheric perturbation develops, the waveguide mode structure of an affected signal begins to change such that the total signal at the receiver either increases or decreases, the direction of the change being a complex function of the path geometry and the perturbation location.

In cases of perturbations on signals with well separated arrival bearings, such as $48.5 \mathrm{kHz}$ and the NLK/NPM pair at Saskatoon, simultaneous zigzags, when they did occur, were usually not mutually coherent and are thus attributed to the effects of multiple perturbed regions. In rare cases of coherence over a wide arrival bearing range (as in Figure 9), it is likely that a perturbed region was located quite close to the receiving station.

Regarding the horizontal size of the perturbed regions, the data suggest that the regions were typically $\sim 50-200 \mathrm{~km}$ in extent. A $\sim 50$-km lower limit is suggested by the regularity with which paths spaced by of order $50 \mathrm{~km}$ were simultaneously perturbed (e.g., NLK and NPM at SA, NSS and NAA at SI) and by the above noted evidence in Saskatoon data of a single active region affecting nearly collinear paths at any one time. A $\sim 200 \mathrm{~km}$ upper limit is suggested by a regular occurrence pattern in the Siple data, in which well defined zigzags were observed in the predawn hours, while the immediately overhead ionosphere appeared to be relatively undisturbed (see Figures 5 and 6). We interpret this to mean that the associated perturbed region was centered near a signal path and within a belt extending roughly $500 \mathrm{~km}$ equatorward of the station (the plasmapause criterion) but did not extend to the region directly overhead (say within $100 \mathrm{~km}$ ).

\subsection{Modulated Electron Precipitation As a Probable Cause of the Zigzag Effect}

It seems clear that the zigzag effect is produced by some type of wave activity at the nighttime $\sim 85 \mathrm{~km}$ lower ionospheric boundary. A promising source of this wave activity is modulated particle precipitation associated with pulsating aurora. Such a source is suggested by similarities in the occurrence patterns of pulsating aurora and zigzag-type events. At Saskatoon and Siple the latter were found to be restricted to periods of moderate to severe planetary disturbance, were concentrated in the postmidnight time sector, and were absent in simultaneous recordings at stations near $L=2$. Similarly, pulsating aurora tends to occur within a belt of latitudes equatorward of the discrete aurora and to be concentrated in the postmidnight, predawn hours following substorm activity in the vicinity of the observing station [e.g., Oguti et al., 1981; Johnstone, 1983; Davidson, 1990; Winkler and Nemzek, 1993; Nemzek et $a l ., 1995]$. The quasi-periods of zigzag fluctuations regularly fall within the observed $\sim 2-20$ s range common in pulsating aurora, although zigzag periods up to $\sim 100$ $s$ have been observed. (As Winkler and Nemzek [1993] point out, pulsating auroral activity can be observed both in the evening and morning hours. VLF zigzag

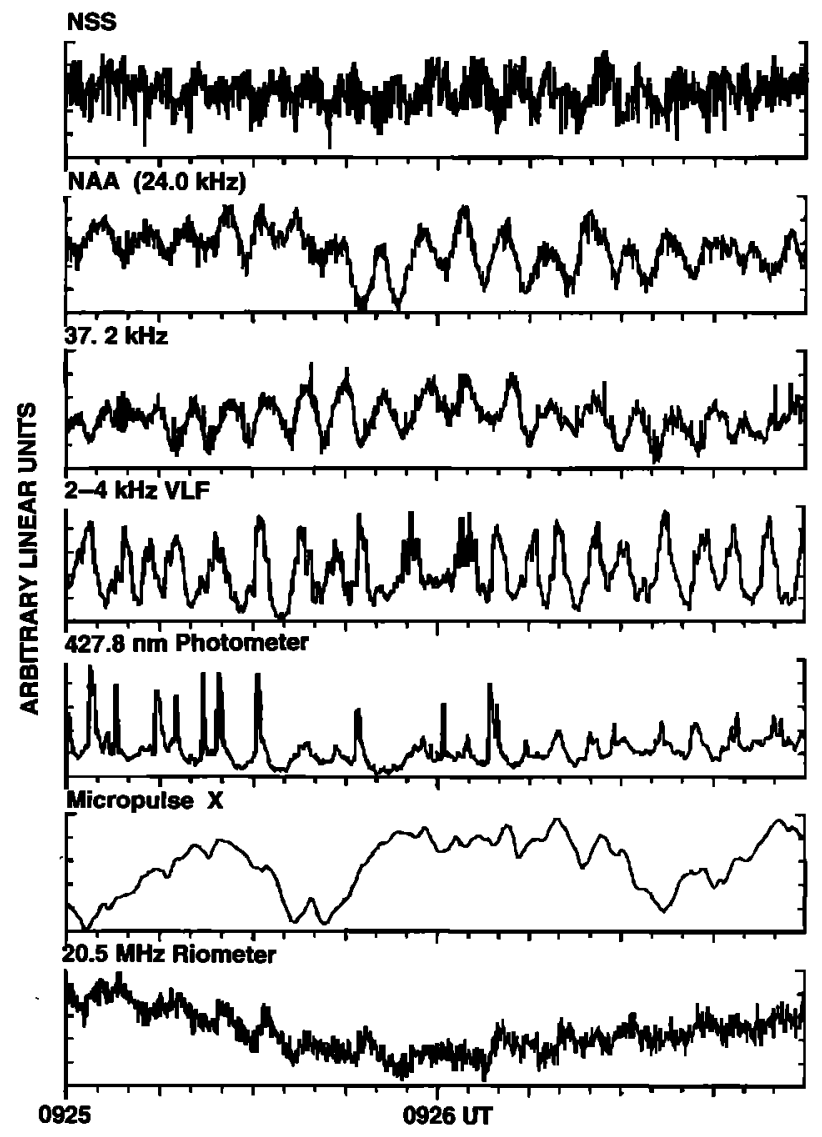

Figure 13. Siple multi-instrument record in a format similar to that of Figures 5 and 6 , showing the occurrence on September 13, 1986 (day 256), of pulsating aurora overhead Siple while zigzag effects were occurring on all three of the displayed VLF transmitter signals. A $37.2 \mathrm{kHz}$ signal channel has been added as the third trace.

activity prior to local midnight has been observed at times of severe magnetic disturbance, but the extent of such occurrences is not yet well established.)

The absence of evidence of overhead or near-overhead precipitation at the actual times of most zigzag events at Siple (indicated on the 1982 charts by a lack of distinctive fluctuations in the data from the magnetic pulsation detector and riometer) is not yet well understood. It may well be attributable to randomness in the spatial distribution of pulsating auroral activity and to the large geographical extent of that distribution in the predawn sector in the aftermath of substorms. This large extent may develop in conjunction with the greater equatorward displacement of the plasmapause near dawn (than near midnight) that commonly occurs when disturbance levels increase following a quiet period [e.g.,Carpenter, 1966; Carpenter et al., 1972]. We therefore suggest that although pulsating aurora over Siple was not usually detected at the actual times of zigzag episodes, it was nevertheless present in the general vicinity of Siple at such times.

This scenario is supported by a case recorded on September 13, 1986, one day prior to the data of Figures 5 and 6 , and illustrated in Figure 13. The format is similar to that of Figures 5 and 6 but with the addition of data on $37.2 \mathrm{kHz}$ (third trace). Two min- 
utes of data are shown for an interval near 0430 MLT. Zigzag activity with period $\sim 7 \mathrm{~s}$ was present on NSS, $\mathrm{NAA}$, and $37.2 \mathrm{kHz}$. The changes on the three channels appeared to be well correlated between $\sim 0925: 50$ and 0926:50 UT but were less clearly so at the other times illustrated. The striking feature of this record is the occurrence of pulsating aurora, as indicated on the fifth panel by the vertical looking 427.8-nm photometer. The quasi-periods of the 427.8-nm fluctuations and the zigzags were approximately the same, at $\sim 7 \mathrm{~s}$, but no consistent phase relation between the two phenomena could be discerned. We therefore suggest that the overhead pulsations and the zigzags involved at least two separate precipitation regions.

In Figure 13, the magnetic pulsation data (sixth trace) did not include evidence of ionospheric conductivity enhancements, as was seen in the data of Figure 5 , possibly because in this case the ionospheric electric field was insufficient to drive the associated currents. On the other hand, the riometer showed fluctuations, especially between 0925 and 0926 UT, a possible indication that the size of the auroral spots was on average larger than in the case of Figure 5.

Note in Figure 13 that between 0926:10 and 0927:00 the $2-4 \mathrm{kHz}$ VLF (fourth trace), a measure of chorus burst activity, exhibited a nearly one-to-one relation to the overhead optical fluctuations. As in previous studies [e.g., Helliwell et al., 1980; Tsuruda et al. 1981], this chorus can be interpreted as the wave activity reponsible for scattering the aurora-producing electrons into the loss cone. Spectrograms of chorus in the 0925-6 minute (nearest available broadband recording) showed individual bursts to consist of clusters of rising traces in the $\sim 2-4 \mathrm{kHz}$ range. Electron energies for cyclotron resonant scattering by these waves at low pitch angles near the equator are estimated to have been in the range $\sim 10-100 \mathrm{keV}$ (assuming propagation near $L=4.3$ under nightside plasmatrough density conditions [e.g., Carpenter and Anderson, 1992]).

Evidence that modulated electron precipitation driven by VLF chorus bursts can also induce trains of VLF waveguide signal pulsations has been presented by Carpenter et al [1985b] and, as noted above, by Corcuff [1996]. Corcuff's data are the most extensive; multiminute episodes of fast developing, slow recovery (i.e., Trimpi-like) pulsations were detected on the NWCKerguelen path $(L \sim 1.4$ to $L \sim 3.7)$ in periods 24 to 48 hours after the onset of severe magnetic storms. At those times the receiver was either expected to be or known to be poleward of the plasmapause projection. The NWC fluctuation envelopes closely resembled the Saskatoon data of Figure 9, having development times of $\sim 0.5$ to $2 \mathrm{~s}$ and recovery times varying between $\sim 4$ and $15 \mathrm{~s}$. In one case for which short intervals of broadband VLF data were available, discrete wave bursts near $4 \mathrm{kHz}$ were found to be correlated on a one-to-one basis with the NWC signal perturbations. Corcuff interpreted the pulsations as a class of Trimpi events, driven by a train of VLF discrete emission bursts.

\subsection{Nature of the Precipitation-Induced Ionospheric Perturbations}

If we postulate that modulated electron precipitation is the source of the zigzag pulsations, what mechanisms can be invoked as links between the pulses of precipitation and ionospheric perturbations at the $\sim 85 \mathrm{~km} \mathrm{VLF}$ reflection height? Three possibilities come to mind and are discussed below: (1) acoustic waves, propagating downward from regions above the VLF reflection level; (2) quasi-static electric fields that perturb the bottomside ionosphere through motor action; (3) secondary ionization production and subsequent decay at the VLF reflection level.

4.3.1. Acoustic waves. The principal energy deposition in pulsating aurora often occurs above $85 \mathrm{~km}$; Brown et al. [1976] observed 19 pulsating aurora events, for all but two of which the lower optical emission limits ranged between 83 and $105 \mathrm{~km}$, the median height being $92 \mathrm{~km}$. In a rocket campaign in Canada to study pulsating aurora in 1980, energy deposition was inferred to be concentrated near $115-120 \mathrm{~km}$ in two of the principal cases studied [McNamara, 1981]. In such situations perturbations at the VLF reflection height might be induced by acoustic waves propagating downward from the precipitation region. For small-amplitude acoustic waves the VLF signal perturbations should be roughly symmetric about their extrema and should vary in amplitude around the mean signal level present before and after the zigzag onset, as in the Siple cases of Figures 1 and 3.

The possibility that pulsating auroral electron precipitation initiates atmospheric acoustic waves that perturb the lower nightime ionosphere is suggested by the fact that acoustic waves with periods in the 10-100 s range have been detected in apparent association with intense auroral precipitation [e.g., Campbell and Young, 1963]. Density variations with respect to the quiescent background level are estimated to be in the range 15-50\% [Newton et al., 1969; Reber et al., 1975]. The waves, propagating at speeds of $200-300 \mathrm{~m} / \mathrm{s}$, are generally attenuated within a few hundred kilometers of the source. Although precipitating energy fluxes in individual pulsating aurora patches should be substantially smaller than in the case of auroral arcs, say of order $10^{-1}$ to $1 \mathrm{erg}-\mathrm{cm}^{-2}-\mathrm{s}^{-1}$ as opposed to $10-100 \mathrm{erg}-$ $\mathrm{cm}^{-2}-\mathrm{s}^{-1}$, the distance from the source of the pulsationinduced acoustic waves to the perturbed underlying reflection region is postulated to be only of order tens of kilometers, so that the integrated path attenuation may not be severe. Furthermore, acoustic waves may be generated more or less coherently over the cross section of the precipitation region, thus causing a beaming effect in the generally downward direction.

In support of the acoustic wave mechanism we note a recent demonstration that acoustic waves with periods of $\sim 2 \mathrm{~min}$, presumably generated in the auroral region and propagating near the mesopause, can produce significant changes in the amplitude of subionospheric VLF signals at middle latitudes [Bell et al., 1994]. Although the period of these waves is much longer than most of those reported in the present paper, we know of no strong reasons why the same effect cannot occur with acoustic waves of smaller period. There are difficulties in explaining observed zigzag amplitudes, however. In order to perturb a subionospheric VLF signal by $\sim 4 \%$ in amplitude, a value less than the $\sim 10-15 \%$ typically observed, calculations similar to those of Poulsen et al. [1993] show that we need a density change of $\sim 50 \%$ at an altitude of $\sim 85 \mathrm{~km}$ over a circular region of $\sim 50 \mathrm{~km}$ radius (horizontal). Thus the pressure of the acoustic wave needs to be comparable to atmospheric pressure at $\sim 85 \mathrm{~km}$ to produce this large change in density. However, if we increase the affected signal path length to 
$200 \mathrm{~km}$, then we need only a $25 \%$ change in electron density at $\sim 85 \mathrm{~km}$. As noted above, we inferred that the horizontal size of the perturbed ionospheric regions was in the range $\sim 50-200 \mathrm{~km}$. Individual auroral pulsation patches may on occasion be this size. Tsuruda et al. [1981] report a case in which a pulsation patch extended $\sim 75 \mathrm{~km}$ in the north-south direction and $\sim 250$ $\mathrm{km}$ in the east-west direction.

4.3.2. Quasi-static electric fields. During disturbed periods ionospheric electric fields transverse to $\mathbf{B}$ of order tens of millivolts per meter are observed in subauroral regions [e.g., Heppner and Maynard, 1987]. During the course of an auroral pulsation the "background" electric field may be strongly perturbed, and this perturbation may be communicated downward to the bottomside of the ionosphere where it may induce changes in the VLF reflection height through ExB drift motions. The extent to which this effect is important may depend upon the scale size of the perturbed regions and the extent to which the electric field is attenuated as the ionosphere becomes more collisional with decreasing altitude. As shown by Mozer and Serlin's [1969] analysis for horizontal electric fields at balloon altitudes, the larger perturbations should map downward more efficiently, and thus there may be a selection mechanism favoring the larger precipitation patches.

It is not clear to what extent this mechanism could explain the various shapes of the zigzag envelopes. However, it would have the advantage of faster communication between the pulsation region and the $\sim 85 \mathrm{~km}$ reflection level, at the Alfven speed instead of the slow $\sim 300-\mathrm{m} / \mathrm{s}$ acoustic wave speed. It might also be more robust. If a perturbation field of $1 \mathrm{mV} / \mathrm{m}$ were to act on the bottomside ionosphere at $L \sim 4$, a drift velocity of $\sim 300 \mathrm{~m} / \mathrm{s}$ could be achieved, and thus vertical displacements of $\sim 1 \mathrm{~km}$ could occur during pulsations with duration of $\sim 5-10 \mathrm{~s}$.

4.3.3. Secondary Ionization. Pulsating aurora is known to have a substantially harder spectrum than the discrete or diffuse aurora [e.g., Brown et al., 1976]. Direct satellite observations by Evans et al. [1987] have shown pulsating precipitation spectra extending from $\sim 5 \mathrm{keV}$ to $\sim 100 \mathrm{keV}$, and rocket measurements during pulsating auroral events have indicated modulated electron fluxes from as low as 2-3 keV [McEwen et al., 1981] to nearly $100 \mathrm{keV}$ [Sandahl et al., 1980].

When a significant part of the electron spectra in a pulsating aurora event exceeds $40 \mathrm{keV}$, patches of secondary ionization should be produced at the VLF reflection height. If the pulses of precipitation are short, a few seconds or less in half width, the density patches and corresponding VLF signal perturbations should grow more rapidly than they decay, as was found early in the March 8, 1988, case at Saskatoon (Figure 10) and in several cases reported by Corcuff [1996]. In such situations the VLF signal perturbation process would essentially be that of the Trimpi effect, with the development time controlled by the characteristics of the driving precipitation pulse and the recovery governed by ionospheric relaxation processes at the reflection level [e.g., Pasko and Inan, 1994]. Furthermore, perturbations in the mean signal level would be expected, and in fact have been observed in fast-rise, slow-decay cases at Siple.

The $\sim 5-10 \mathrm{~s}$ recoveries seen in cases such as that of Figure 9, in Corcuffs [1996] data, and in earlier reports on perturbations of Siple transmitter signals prop- agating in the Earth-ionosphere waveguide at $L>4$ [e.g., Carpenter et al., 1985b; Hurren et al., 1986] appear to be common features of Trimpi-like precipitation events poleward of the plasmapause. They are notably faster than the $\sim 20-40$ s recoveries normally observed in whistler-driven Trimpi events at plasmasphere latitudes. As suggested by Hurren et al. [1986], this may be due to the deposition of energy at lower $D$ region altitudes, where ionization loss rates due to attachment are higher [e.g., Inan et al., 1988; Pasko and Inan, 1994].

Some of the more symmetric zigzag effects may also be understandable in terms of bursts of secondary ionization at and below $85 \mathrm{~km}$. In such situations the longer-pulsation development times and hence greater symmetry around extrema may simply be due to increased duration of the electron precipitation bursts. Chorus burst emissions vary in time duration, and since individual chorus elements tend to rise in frequency with time, the ionospheric arrival times of electrons that they induce to precipitate should tend to spread in time as a function of energy, rather than to converge as in the case of scattering by falling-tone whistlers from lightning [e.g., Chang and Inan, 1985]. Thus variations in the development time of waveguide signal pulsations might be attributable to changes in the duration and/or slope of associated chorus bursts, and by implication to corresponding changes in the instability that gives rise to the chorus elements. Such an explanation would seem consistent with the case of March 8, 1988 at Saskatoon, illustrated in Figures 9, 10, and 11. The pulsation activity began with fast onsets and then evolved such that the development time/recovery time ratio increased relatively steadily over a $\sim 2$-hour period while the phase relationship between NLK and NPM pulsations remained roughly the same.

A problem with secondary ionization as an exclusive mechanism is that it requires the development and recovery times, presumably controlled by different physical processes, to be closely matched in a large fraction of the observed cases. Also, it may fail to explain some of the faster recovery rates, of order $3 \mathrm{~s}$, such as are illustrated in Figure 13. On balance therefore it appears necessary to invoke more than one mechanism to explain the data.

The relative occurrence rates of the more symmetric zigzags and the Trimpi-like events have yet to be established. However, the occurrence findings thus far seem broadly consistent with our expections that the electron precipitation fluxes in pulsating aurora become on average more intense and/or harder and also penetrate to lower latitudes as the level of geomagnetic activity increases. This is supported by the apparent tendency of zigzag activity at Kerguelen $(L \sim 3.7)$ to be concentrated in the aftermath of severe disturbances, when $K p$ reached 6 or more, and for a substantial number of the Kerguelen zigzag events to be Trimpi-like in form [Corcuff, 1996]. In contrast our findings from stations Saskatoon and Siple at $L>4$ show that zigzag events regularly occurred under only moderately disturbed conditions, with $K p=3-4$ and that at least at Siple $(L \sim 4.3)$ the symmetric zigzag form was more common.

\subsection{Other Ionospheric Phenomena and Their Possible Relation to the Zigzag Effect}

As noted above, radio signals probing the ionosphere at and above medium frequencies have been found to 
fluctuate with periods ranging from $\sim 10 \mathrm{~s}$ to several minutes, sometimes in synchronism with fluctuations in the Earth's magnetic field as registered on magnetometers. However, many of these observations have been made at relatively low latitudes, near $L=2$, and in daytime [e.g., Sutcliffe and Poole, 1984; Tedd et al., 1989], conditions that differ substantially from those of zigzag activity. The mechanisms that have been proposed to explain the observations [e.g., Rishbeth and Garriott, 1964; Sutcliffe and Poole, 1989; Tedd et al., 1989] mostly involve the perturbing effects on the ionosphere of hydromagnetic waves originating in the magnetosphere, rather than those of modulated particle precipitation. Nevertheless, to the extent that such observations have been made at latitudes near to and poleward of the plasmapause [e.g., Jarvis and Gough, 1988], the possibility should be considered that perturbations in the refractive index induced by modulated particle precipitation are involved.

\subsection{Remaining Problems}

There is much more to learn about the zigzag effect both in terms of experimental observations and interpretation. There is an obvious need to test the idea of pulsating electron precipitation as the "source" of the zigzag effect. To this end there is a need to localize, perhaps through additional VLF signal paths, the regions of ionospheric perturbations, to verify the occurrence of correlated pulsations in electron precipitation, and if such pulsations are detected, to determine how the properties of the zigzag effect are influenced by the incident electron spectrum. More information is needed relating the occurrence of zigzags to the development phases of substorms.

A theory of the zigzag effect must explain a number of observations, including the finding that at Saskatoon the fluctuation amplitudes regularly reached $10-15 \%$ of the mean signal level and sometimes exceeded $50 \%$ of that level, thus tending to be larger than the changes in amplitude observed within the dense plasmasphere by means of the classic Trimpi effect. There is a need to explain why zigzag activity at Saskatoon was more extensive on the west-east NLK/NPM paths than on the east-west NAA and NSS paths.

We do not understand the difference between the frequently episodic nature of the zigzag activity at Siple and its more continuous character at Saskatoon. An important factor may be hemispheric differences in the affected ionospheres and in the properties of pulsating aurora such as might be imposed by differences in the geomagnetic field. Some of the apparent differences may be due to the greater use of visual inspection in the case of the Siple data and of more extensive reprocessing in the case of Saskatoon.

\section{Conclusions}

Subionospheric VLF transmitter signals received at several ground stations in the $L=4-4.5$ range have been found to exhibit pulsating behavior with typical periods in the $\sim 5-60 \mathrm{~s}$ range, but sometimes reaching $\sim 100 \mathrm{~s}$. The amplitude-time shape of the pulsations was often triangular or zigzag-like, hence the term zigzag effect. Departures from this form were usually in the direction of faster rise than decay and of pulse widths that were shorter than the interpulse interval. Episodes of zigzag activity were found to occur widely during the postmidnight hours following the occurrence of substorm activity and were not observed during geomagnetically quiet periods. The activity appeared to be caused by localized perturbations at the $85-\mathrm{km}$ nighttime VLF reflection height in regions poleward of the plasmapause.

At Siple Station, Antarctica $(L \sim 4.3)$, the activity frequently appeared in the hour or two before sunrise (along the signal path) in the form of multiminute trains of quite regular fluctuations. At Saskatoon, Canada ( $L \sim 4.2$ ), the activity was found to be more extensive in duration.

Zigzag effects on the nearly collinear NLK and NPM signal paths to Saskatoon, that is, paths with great circle separations of order $50 \mathrm{~km}$ at distances of several hundred kilometers from the receiver, were found to be closely correlated. The fluctuations tended to be either in phase or out of phase, with time lags between correlated extrema of order $\sim 1 \mathrm{~s}$.

From the present research and other work we infer that the ionospheric perturbations associated with zigzags at Saskatoon and Siple were centered within $\sim 500 \mathrm{~km}$ of the stations and within $\sim 100-200 \mathrm{~km}$ of each of the affected signal paths. A single perturbed ionospheric region appears to have been active at any one time in producing much of the observed zigzag activity on the nearly collinear NLK/NPM paths to Saskatoon. The effects of multiple perturbed regions were often manifested in a lack of coherence between simultaneous zigzags on paths with widely different arrival bearings. The horizontal extent of the perturbed regions is estimated to have been in the $50-200 \mathrm{~km}$ range.

The existing evidence, supported by Corcuff's [1996] study of the NWC (Australia) to Kerguelen ( $L \sim 3.7$ ) path, suggests that the underlying cause of the effect was pulsating auroral precipitation. It is not clear what mechanisms provide the coupling between the precipitation and the perturbations that develop at the $\sim 85$ $\mathrm{km}$ VLF reflection height. In the case when the incident particle energies are predominantly $<40 \mathrm{keV}$ and precipitation is concentrated above $85 \mathrm{~km}$, downward propagating acoustic waves or quasi-static electric fields are candidate mechanisms. The latter would involve vertical motions of the bottomside ionosphere induced as ExB drifts by the perturbation electric field, a field that originates when the background ionospheric electric field is perturbed by a local enhancement in ionospheric conductivity. When the spectrum of incident electrons extends well above $40 \mathrm{keV}$, as in the case of electron microbursts, secondary ionization should develop at the reflection height and could satisfactorily explain those zigzag observations in which the signal fluctuations rise substantially faster than they decay. However, this mechanism is not likely to explain more than a part of the large body of zigzag cases with nearly symmetric fluctuation envelopes.

There remains much to learn about the zigzag phenomenon, for example, about its relation to various forms of pulsating auroral precipitation, about stationto-station variations in the extent to which the activity is episodic or continuous, and about possible connections between the effect and previously reported fluctuations in ionospheric probing signals at medium frequencies and above.

Acknowledgments. The research at Stanford was sponsored in part by the Division of Polar Programs of the Na- 
tional Science Foundation under grants for work at Palmer and Siple Stations, including grant DPP89-18326, and in part by the Atmospheric Sciences Section of the NSF. under grant 9113012 for work on data from Saskatoon, Stanford, and Lake Mistissini. A portion of the work by D. C. was performed during a working visit to the British Antarctic Survey, Cambridge. The work by M. G., at the time of the University of Strasbourg, was accomplished during a working visit to Stanford University. The Siple riometer data and other 1986 Siple data sets derived from digital recordings were obtained by the University of Maryland with support from NSF grant OPP-8610061. The present work with these data at Maryland is being supported by grant OPP9505823. We thank D. Detrick for digital reprocessing of that data. We thank R. Arnoldy and L. Cahill Jr. for use of Siple magnetic pulsation data, S. Mende and J. Doolittle for photometer data from Siple, and D. McEwen for magnetometer data from Saskatoon.

The editor thanks S. B. Mende and I. Sandahl for their assistance in evaluating this paper.

\section{References}

Arnoldy, R. L., K. Dragoon, L. J. Cahill Jr., S. B Mende, and T. J. Rosenberg, Detailed correlations of magnetic field and riometer obsérvations at $L=4.2$ with pulsating aurora, J. Geophys. Res., 8\%, 10449, 1982.

Bell, T. F., U. S. Inan, and J. T. Chen, VLF remote sensing of traveling ionospheric disturbances, Eos Trans. AGU, 75, Spring Meet. Suppl., 488, 1994.

Brown, N. B., T. N. Davis, T. J. Hallinan, and H. C. Stenbaek-Nielsen, Altitude of pulsating aurora determined by a new instrumental technique, Geophys. Res. Lett., 3, $403,1976$.

Burgess, W. C., and U. S. Inan, The role of ducted whistlers in the precipitation loss and equilibrium flux of radiation belt electrons, J. Geophys. Res., 98, 15,643, 1993.

Campbell, W. H., and J. M. Young, Auroral-zone observations of infrasonic pressure waves related to ionospheric disturbances and geomagnetic activity, J. Geophys. Res., $68,5909,1963$.

Carpenter, D. L., Whistler studies of the plasmapause in the magnetosphere, 1: Temporal variations in the position of the knee and some evidence on plasma motions near the knee, J. Geophys. Res., 71, 693, 1966.

Carpenter, D. L., and R. R. Anderson, An ISEE/whistler model of equatorial electron density in the magnetosphere, J. Geophys. Res., 97, 1097, 1992.

Carpenter, D. L., and C. G. Park, On what ionospheric workers should know about the plasmapause-plasmasphere Rev. Geophys., 11, 133, 1973.

Carpenter, D. L., K. Stone, J. C. Siren, and T. L. Crystal, Magnetospheric electric fields deduced from drifting whistler paths, J. Geophys. Res., 77, 2819, 1972.

Carpenter, D. L., U. S. Inan, and J. P. Katsufrakis, Evidence of oscillating behavior of the nighttime $D$-region at middle latitudes, Eos Trans. $A G U, 66,349,1985$ a.

Carpenter, D. L., U. S. Inan, E. W. Paschal, and A. J. Smith, A new VLF method for studying burst precipitation from the magnetosphere, J. Geophys. Res., 90, 4383, 1985b.

Chan, K. L., D. P. Kanellakos, and O. G. Villard, Correlation of short-period fluctuations of the Earth's magnetic field and instantaneous frequency measurements, $J$. Geophys. Res., 67, 2066, 1962.

Chang, H. C., and U. S. Inan, Lightning-induced electron precipitation from the magnetosphere, J. Geophys. Res., $90,1531,1985$

Clark, T. D. G., A study of quasi-periodic electron precipitation at Halley, Antarctica, Ph.D. thesis, Univ. of Sheffield, 1991, Sheffield, England.

Corcuff, Y., Trimpi events and other amplitude perturbations observed during 1991 at Kerguelen $(L=3.7)$ on the subionospheric NWC signal, J. Atmos. Terr. Phys., 58, 1367, 1996.

Davidson, G. T., Pitch-angle diffusion and the origin of temporal and spatial structures in morningside aurora, Space Sci. Rev., 53, 45, 1990.
Davies, K., and D. M. Baker, On frequency variations of ionospherically propagated HF radio signals, Radio Sci., $1,545,1966$.

Davies, K., and G. K. Hartmann, Short-period fluctuations in total columnar electron content, J. Geophys. Res., 81, $3431,1976$.

Devlin, J. C., P. L. Dyson, and P. R. Hammer, Smallamplitude, short- period waves in the $E$ - and $F$-regions of the ionosphere, Nature, 268, 319, 1977.

Dingle, B., and D. L. Carpenter, Electron precipitation induced by VLF noise bursts at the plasmapause and detected at conjugate ground stations, J. Geophys. Res., $86,4597,1981$.

Evans, D. S., G. T. Davidson, H. D. Voss, W. L. Imhof, J. Mobilia, and Y. Chiu, Interpretation of electron spectra in morningside pulsating aurorae, J. Geophys. Res., 92, 12295, 1987.

Glangeaud, F., C. Lathuillere, M. Lambert, and Z. Y. Zhao, Pc 3-4 ULF magnetic variations measured in the ionosphere by EISCAT, J. Geophys. Res., 90, 8319, 1985.

Helliwell, R. A., J. P. Katsufrakis, and M. Trimpi, Whistlerinduced amplitude perturbation in VLF propagation, $J$ Geophys. Res., $78,4679,1973$.

Helliwell, R. A., S. B. Mende, J. H. Doolittle, W. C. Armstrong, and D. L. Carpenter, Correlations between $\lambda 4278$ optical emissions and VLF wave events observed at $L \sim 4$ in the Antarctic, J. Geophys. Res., 85, 3376, 1980.

Heppner, J. P., and N. C. Maynard, Empirical high-latitude electric field models, J. Geophys. Res., 92, 4467, 1987.

Hurren, P. J., A. J. Smith, D. L. Carpenter, and U. S. Inan, Burst precipitation induced perturbations on multiple VLF propagation paths in Antarctica, Ann. Geophys., Ser. $A, 4,311,1986$.

Inan, U. S., and D. L. Carpenter, On the correlation of whistlers and associated ionospheric perturbations, J. Geophys. Res., 91, 3106, 1986.

Inan, U. S., W. C. Burgess, T. G. Wolf, D. C. Shafer, and R. E. Orville, Lightning-associated precipitation of $\mathrm{MeV}$ electrons from the inner radiation belt, Geophys. Res. Lett. 15, 172, 1988 .

Inan, U. S., A Slingeland, V. P. Pasko, and J. V. Rodriguez, VLF and LF signatures of mesospheric/lower ionospheric response to lightning discharges, J. Geophys. Res., 101, $5219,1996$.

Jarvis, M. J., and H. Gough, Digital ionosonde observations of Pc3-4 pulsations across the plasmapause, Planet. Space Sci., 36, 733, 1988.

Johnstone, A. D., The mechanism of pulsating aurora, Ann. Geophys., 1, 397, 1983 .

Lathuillere, C., F. Glangeaud, J. L. Lacoume, and G. Lejeune, Relationship between ionospheric electric field and ground magnetic pulsations in the PC 3 domain at midlatitude, J. Geophys. Res., 86, 7669, 1981.

McEwen, D. J., E. Yee, B. A. Whalen, and A. W. Yau, Electron energy measurements in pulating auroras, Can. J. Phys., 59, 1106, 1981.

McNamara, A. G., Plasma measurements in pulsating auroras, Can. J. Phys., 59, 1083, 1981.

Mozer, F. S., and R. Serlin, Magnetospheric electric field measurements with balloons, J. Geophys. Res., 74, 4739, 1969.

Nemzek, R. J., R. Nakamura, D. N. Baker, R. D. Belion, D. J. McComas, M. R. Thomsen, and T. Yamamoto, The relationship between pulsating auroras observed from the ground and energetic electrons and plasma density measured at geosynchronous orbit, J. Geophys. Res., 100, 23935, 1995.

Newton, G. P., D. T. Pelz, and H. Volland, Direct in situ measurements of wave propagation in the neutral thermosphere, J. Geophys. Res., 74, 183, 1969.

Oguti, T., S. Kokubun, K. Hayashi, K. Tsuruda, S. Machida, T. Kitamura, O. Saka, and T. Watanabe, Statistics of pulsating auroras on the basis of all-sky TV data from five stations, Can. J. Phys., 59, 1150, 1981.

Oguti, T., J. H. Meek, and K Hayashi, Multiple correlation between auroral and magnetic pulsations, J. Geophys. Res., 89, 2295, 1984. 
Okuzawa, T., and K. Davies, Pulsations in total columnar electron content, J. Geophys. Res., 86, 1355, 1981.

Pasko, V. P., and U. S. Inan, Recovery signatures of lightningassociated VLF perturbations as a measure of the lower ionosphere, J. Geophys. Res., 99, 17523, 1994.

Poulsen, W. L., T. F. Bell, and U. S. Inan, Three-dimensiona modeling of subionospheric VLF propagation in the presence of localized D region perturbations associated with lightning, J. Geophys. Res., 95, 2355, 1990.

Poulsen, W. L., T. F. Bell, and U. S. Inan, The scattering of VLF waves by localized ionospheric disturbances produced by lightning-induced electron precipitation, $J$. Geophys. Res., 98, 15553, 1993.

Reber, C. A., A. E. Hedin, D. T. Pelz, W. E. Potter, and L. H. Brace, Phase and amplitude relationships of wave structure observed in the lower thermosphere. J. Geophys. Res., 80, 4576, 1975.

Rishbeth, H., and O. K. Garriott, Relationship between simultaneous geomagnetic and ionospheric oscillations, $R a-$ dio Sci., 68, 339, 1964.

Rosenberg, T. J., R. A. Helliwell, and J. P. Katsufrakis, Electron precipitation associated with discrete very-lowfrequency emissions, J. Geophys. Res., 76, 8445, 1971.

Rycroft, M. J., Enhanced energetic electron intensities at $100 \mathrm{~km}$ altitude and a whistler propagating through the plasmasphere, Planet. Space Sci., 21, 239, 1973.

Sandahl, I., L. Eliasson, and R. Lundin, Rocket observations of precipitating electrons over a pulsating aurora, Geophys. Res. Lett., 7, 309, 1980.

Sutcliffe, P. R., and A. W. V. Poole, Low latitude Pc 3 pulsations and associated ionospheric oscillations measured by a digital chirp ionosonde, Geophys. Res. Lett., 11, $1172,1984$.

Sutcliffe, P. R., and A. W. V. Poole, Ionospheric doppler and electron velocities in the presence of ULF waves, $J$. Geophys. Res., 94, 13,505, 1989.

Tedd, R. L., K. D. Cole, and P. L. Dyson, The association between ionospheric and geomagnetic pulsations in the Pc3-4 range at mid- latitudes, Planet. Space Sci., 37, $1079,1989$.
Tsuruda, K., S. Machida, T. Oguti, S. Kokubun, K. Hayashi, T. Kitamura, O. Saka, and T. Watanabe, Correlations between the very low frequency chorus and pulsating aurora observed by low-light-level television at $L \sim 4.4, \mathrm{Can}$. J. Phys., 59, 1042, 1981.

Voss, H. D., W. L. Imhof, M. Walt, J. Mobilia, E. E. Gaines, J. B. Reagan, U. S. Inan, R. A. Helliwell, D. L. Carpenter, J. P. Katsufrakis, and H. C. Chang, Lightning-induced electron precipitation, Nature, 312, 740, 1984.

Winkler, J. R., and R. J. Nemzek, Observations of the pulsating phase of auroras observed at Minneapolis during the peak of solar cycle 22, in Auroral Plasma Dynamics, Geophys. Monogr. Ser., vol. 80, edited by R. L. Lysak, p. 1, AGU, Washington, D.C., 1993.

T.F.Bell, D.L.Carpenter, and U.S.Inan, Space, Telecommunications and Radioscience Laboratory, Stanford University, Stanford, CA 94305. (email: bell@nova.stanford.edu; dlc@nova.stanford.edu; inan@nova.stanford.edu)

T. D. G. Clark, British Geological Survey, Natural Environment Research Council, Edinburgh, United Kingdom.

M. Gland, National Center for Atmospheric Research, Boulder, CO 80307.

J. LaBelle, Department of Physics and Astronomy, Dartmouth College, Hanover, NH 03755. (email: jlabelle@einstein.dartmouth.edu)

T. J. Rosenberg, Institute for Physical Science and Technology, University of Maryland, College Park, MD 20742. (email: rosenberg@uap.umd.edu)

A. J. Smith, British Antarctic Survey, Natural Environment Research Council, Cambridge, CB3 OET England.

V.S. Sonwalkar, Electrical Engineering Department, University of Alaska Fairbanks, POB 755900, Fairbanks, AK 99775. (email: ffvss@aurora.alaska.edu)

(Received March 1, 1996; revised September 16, 1996; accepted September 17, 1996.) 